This item was submitted to Loughborough's Research Repository by the author.

Items in Figshare are protected by copyright, with all rights reserved, unless otherwise indicated.

\title{
A segmented fuel cell unit with functionally graded distributions of platinum loading and operating temperature
}

PLEASE CITE THE PUBLISHED VERSION

https://doi.org/10.1016/j.cej.2020.126889

PUBLISHER

Elsevier

VERSION

AM (Accepted Manuscript)

PUBLISHER STATEMENT

This paper was accepted for publication in the journal Chemical Engineering Journal and the definitive published version is available at https://doi.org/10.1016/j.cej.2020.126889

LICENCE

CC BY-NC-ND 4.0

\section{REPOSITORY RECORD}

Xing, Lei, Yuanxiang Xu, Željko Penga, Qian Xu, Huaneng Su, Frano Barbir, Weidong Shi, and Jin Xuan. 2020. "A Segmented Fuel Cell Unit with Functionally Graded Distributions of Platinum Loading and Operating Temperature”. Loughborough University. https://hdl.handle.net/2134/13095653.v1. 


\section{A segmented fuel cell unit with functionally graded distributions of platinum loading and operating temperature}

Lei Xing ${ }^{1,2, *}$, Yuanxiang $\mathrm{Xu}^{1}$, Željko Penga ${ }^{3,4}$, Qian $\mathrm{Xu}^{5}$, Huaneng $\mathrm{Su}^{5}$, Frano Barbir ${ }^{3,4}$, Weidong $\mathrm{Shi}^{6 *}$, Jin Xuan $^{7}$

1. Institute of Green Chemistry and Chemical Technology, Jiangsu University, Zhenjiang, China

2. Department of Engineering Science, University of Oxford, Oxford, UK

3. Faculty of Electrical Engineering, Mechanical Engineering and Naval Architecture, University of Split, Split, Croatia

4. Center for Excellence for Science and Technology - Integration of Mediterranean Region, University of Split, Split, Croatia

5. Institute of Energy Research, Jiangsu University, Zhenjiang, China

6. School of Chemistry and Chemical Engineering, Jiangsu University, Zhenjiang, China

7. Department of Chemical Engineering, Loughborough University, Loughborough, LE11 3TU, UK

Correspondence

Lei Xing (inglei1314@gmail.com; xinglei@ujs.edu.cn)

Weidong Shi (swd1978@ujs.edu.cn) 


\begin{abstract}
Desired electrochemical reaction and mass transport rates vary in the operation of PEM fuel cells due to the inhomogeneous spatial distribution of reactants and products. A segmented fuel cell unit was manufactured and a comprehensive model was developed to study the effect of the graded distributions of platinum loading and operating temperature, to simultaneously save the usage of platinum, improve the cell performance and maintain the homogeneity of current density. The increase of temperature towards the cathode outlet improved the reaction kinetics and reduced the liquid water content along the gas flow direction, which decreased the required platinum loading. A large temperature gradient may lead to starvation of oxygen near the cathode outlet due to the dilution of the increased vapor content. A systematical design of the gradients of platinum loading and temperature achieved an improved cell performance and saved the usage of Pt-based catalysts without worsening the homogeneity of current density.
\end{abstract}

Keywords: PEM fuel cell, graded design, platinum loading, temperature, segmented cell 


\section{Introduction}

Through decades of vigorous development, proton exchange membrane (PEM) fuel cell, a promising energy converting device operated with environmental-friendly resources and with zero-emission potentials, are moving forward to practical applications from laboratories [1-3]. However, the use of precious metals as reaction catalysts hampers the pathway of PEM fuel cells towards widespread applications. In particular, the homogeneous distribution of platinum-based catalysts inside the porous electrode of a traditional fuel cell exacerbates the cost since a large portion of catalysts may place in the regions of the electrodes where only low electrochemical activity is required. Therefore, increasing concerns are focused on designing novel functionally graded fuel cells to reduce the usage of precious catalysts [4-7].

Within the porous electrodes of PEM fuel cells, effective electrochemical reactions only occur on the triple-phase boundaries (TPBs) sheared by void space (for gas transport), ionomer (for proton transport) and $\mathrm{Pt} / \mathrm{C}$ (for electron transport). Thus, the design of functionally graded electrodes typically includes the inhomogeneous distributions of electrode porosity [8-13], ionomer loading [14-17] and catalyst loading [18-28] along both the in-plane and through-plane directions. As one of the most critical design variables, platinum loading attracts great attention due to its significant effect on reaction activity, durability and cost of the cell. Generally speaking, reaction activity is directly correlated with platinum loading as long as the carbon-supported platinum (Pt/C) particles are well dispersed. Santis et al. [19] designed a tailored cathode with redistributed catalyst loading along the channel, with the lower loading near the inlet and higher near the outlet of the cathode. For the same average platinum loading of $0.3 \mathrm{mg} \mathrm{cm}^{-2}$, an increase in platinum loading along the gas flow direction improved the cell performance by $20 \%$ at $0.5 \mathrm{~V}$. To improve catalyst utilization and reduce platinum usage without remarkable loss in cell performance, Prasanna et al. [20] increased the local electrochemical reaction rate by applying a catalyst-gradient electrode method to singlecell fabrication. Since more catalysts were placed near the outlet of the cathode channel, the increased catalyst loading counteracted the depletion of oxygen along the channel. With the help of the catalystgradient electrode, the cell voltage increased from 0.56 to $0.61 \mathrm{~V}$ at a current density of $0.9 \mathrm{~A} \mathrm{~cm}^{-2}$, and the peak power density increased from 0.5 to $0.59 \mathrm{~W} \mathrm{~cm}^{-2}$ with a platinum loading of $0.3 \mathrm{mg} \mathrm{cm}^{-2}$. Based on 
the findings of the above studies, an increase in platinum loading towards the cathode outlet is considered as an effective way to improve cell performance when platinum loading is the sole design parameter. Recently, the design of gradient cathode catalyst layer was used for mitigating Pt degradation in PEM fuel cells by Zheng et al. [27]. The optimization of current density distribution by means of Pt tuning was also implemented in mitigating the degradation issues of DMFCs (direct methanol fuel cells) [28], showing a great potential of the functionally graded electrode for various electrochemical devices.

In comparison with platinum loading, the operating temperature has a more comprehensive effect on the cell performance. Higher operating temperature is desirable due to the positive impact of temperature on a variety of kinetic, transport and phase transfer processes [29-31]. However, operating fuel cells at a hightemperature condition faces a great challenge of mechanical and chemical failure of Nafion ${ }^{\circledR}$ membrane [32]. Due to the direct effect of temperature on water saturation pressure, the mole fraction of vapor in the gas mixture could be controlled by the graded design of operating temperature. Based on this fact, Penga et al. [33] manufactured a variable-temperature flow field for PEM fuel cells, in which a five-segment cell with graded operating temperatures was implemented. The segment close to the cathode outlet was operated at a higher temperature, so that more moisture generated by the oxygen reduction reaction (ORR) is retained. The novel design reduced mass transport losses at the high current density by minimizing the water flooding within the cell, which achieved a high relative humidity along the entire flow field when dry reactant gas was used at the cathode. Graded platinum loading could also control the vapor content in the gas mixture. To hydrate the PEM using the self-produced water, Lee et al. [21] placed more platinum near the cathode inlet, and platinum loading gradually decreased towards the cathode outlet. Improvement of cell performance by approximately $17 \%$ under non-humidified conditions resulted from the catalyst-graded design in comparison with the conventional design. For fully humidified inlet gas at the cathode, the increased water carrying capacity (WCC) of the gas mixture at high temperature may lead to reactant gas starvation due to the diluted oxygen concentration [34]. Segmented cells have been successfully used in PEM and other fuel cells and also electrolysis [35-37]. In most of previous work, segmented cells were used for diagnosis purposes, e. g. characterization of the inhomogeneous distributions of current density 
and temperature along the gas flow direction. Due to the significant effects of platinum loading and operating temperature, the simultaneously design of these two variables should be a promising solution to improve the cell performance and reduce the usage of previous catalysts. However, to the best of the knowledge of the authors, the interaction of platinum loading and operating temperature has not been studied. Thus, we for the first time combine the effects of platinum loading and operating temperature by designing a graded cell with platinum loading decreasing, and temperature increasing, from the cathode inlet towards the outlet. Along the gas flow direction, the loss of reaction activity due to less platinum loading is compensated by the higher operating temperature. To the best knowledge of the authors, there is no previous research integrated the graded design of both platinum loading and operating temperature in a single fuel cell unit.

In this work, a segmented fuel cell unit was designed and manufactured, in which platinum loading and operating temperature of five individual segments are controlled separately. Various platinum loading and temperature gradients were compared to study the synergetic effect of platinum loading and temperature on cell performance and current density distribution. The aim is to reduce the overall amount of precious Pt-based catalyst and maintain homogeneous current density distribution along the channel without significantly sacrificing the cell performance at medium and high current densities. Along the gas flow direction towards the cathode outlet, the loss of cell performance at reduced platinum loading is compensated by the improvement of catalytic activity at high temperature. The optimal gradients of the two design variables could simultaneously save the usage of platinum, improve cell performance and maintain the homogeneity of current density. Our work provides a promising solution for the next-stage commercialization of PEM fuel cells.

\section{Model development}



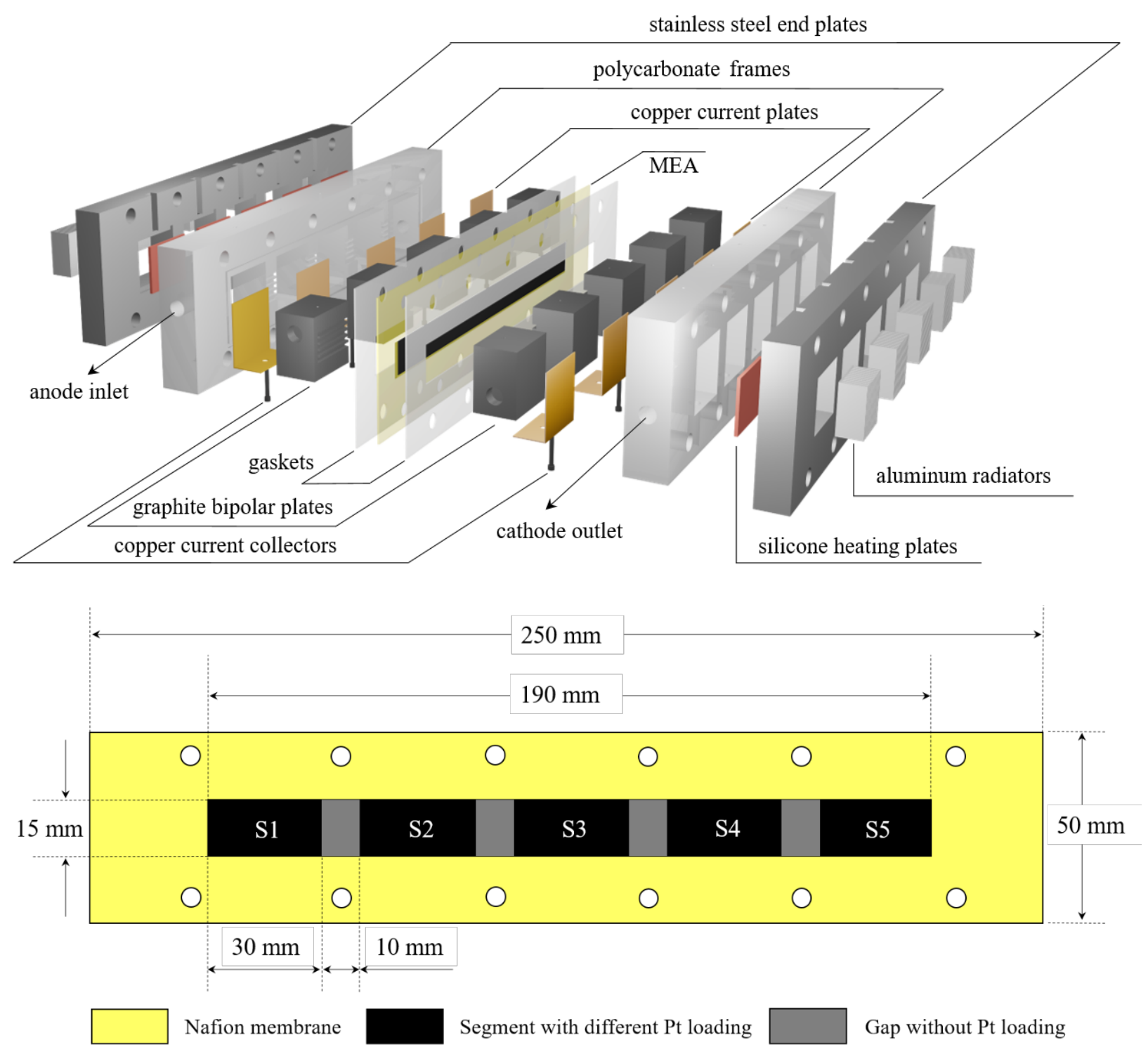

Fig. 1 Annotated structure of the segmented fuel cell unit and MEA

The model is developed based on a two dimensional along-the-channel geometry consisted of a pair of gas diffusion layer (GDL), micro porous layer (MPL), catalyst layer (CL) on the anode and cathode, respectively. A proton exchange membrane is sandwiched in between. It was assumed that the CLs were constructed by plenty of carbon agglomerates, in which platinum particles were uniformly distributed inside carbon black. The agglomerates were treated as spherical pellets, consisted of platinum, carbon powder, and hydrophobic materials, e. g PTFE, glued together by ionomer as a binder. All agglomerates were connected by the thin ionomer films surrounded each carbon agglomerate. Details of the CLs constructed 
by agglomerates could be found elsewhere [17]. The geometry and more details of the segmented fuel cell unit in this study are shown in Fig.1. The details of the MEA preparation and cell manufacturing is given in Section 3.

\subsection{Governing equations}

The transport of compressible Newtonian fluids through the channel and porous electrode at steady state was described by continuity equation and Navier-Stokes equation, in which the pressure and velocity of gas mixture were calculated.

$$
\begin{gathered}
\nabla \cdot\left(\rho_{g} \mathbf{u}_{g}\right)=S_{m} \\
\frac{1}{\varepsilon^{2}} \rho_{g}\left(\mathbf{u}_{g} \cdot \nabla\right) \mathbf{u}_{g}=-\nabla p+\nabla \cdot \frac{\mu_{g}}{\varepsilon}\left[\nabla \mathbf{u}_{g}+\left(\nabla \mathbf{u}_{g}\right)^{T}-\frac{2}{3}\left(\nabla \cdot \mathbf{u}_{g}\right) I\right]
\end{gathered}
$$

where $\mathbf{u}_{g}\left(\mathrm{~m} \mathrm{~s}^{-1}\right), \rho_{g}\left(\mathrm{~kg} \mathrm{~m}^{-3}\right)$ and $\mu_{g}(\mathrm{~Pa} \mathrm{~s})$ are the velocity, density and viscosity of the gas mixture, respectively. $p(\mathrm{~Pa})$ is pressure, $I$ is the identity matrix, $S_{m}\left(\mathrm{~kg} \mathrm{~m}^{-3} \mathrm{~s}^{-1}\right)$ is the source term, representing the source/sink of gas mixture, including hydrogen, oxygen and water vapor.

The conservation of species was described by Maxwell-Stefan equation, in which the mole fraction of gas species $i$ in gas mixture was calculated.

$$
\rho_{g}\left(\mathbf{u}_{g} \cdot \nabla\right) x_{i}^{g}-\nabla \cdot\left\{\rho_{g} \sum_{j} D_{i j}^{e f f}\left[\nabla x_{j}^{g}+\frac{\nabla p}{p}\left(x_{j}^{g}-w_{j}^{g}\right)\right]\right\}=S_{i}^{g}
$$

where $x_{i}^{g}$ and $w_{j}^{g}$ are the mole fraction and mass fraction of species $i$ in the gas mixture, $D_{i j}^{e f f}\left(\mathrm{~m}^{2} \mathrm{~s}^{-1}\right)$ is the effective diffusivity, $S_{i}^{g}\left(\mathrm{~mol} \mathrm{~m}^{-3} \mathrm{~s}^{-1}\right)$ is the source term, representing the source/sink of species $i$. Considering the filling of liquid water inside the porous electrode, the effective diffusivity is corrected by Bruggeman correlation as follow:

$$
D_{i j}^{e f f}=D_{i j}^{0}[(1-s) \varepsilon]^{1.5}
$$


where $D_{i j}^{0}\left(\mathrm{~m}^{2} \mathrm{~s}^{-1}\right)$ is the intrinsic binary diffusivity of species i and j, $\varepsilon$ is the electrode porosity and $s$ is the water saturation, defined as the volume fraction of liquid water within the porous electrode, which is calculated by the following equation based on the volume of fluid (VOF) method [38].

$$
\rho_{w} D_{c} \nabla^{2} s+\left(\frac{s}{1-s}\right)^{3} \frac{\rho_{w} k_{p} \mu_{w}^{g}}{\mu_{g} \mu_{w}^{l}} \nabla^{2} p=M_{w} S_{w}^{l}
$$

where $D_{c}\left(\mathrm{~m}^{2} \mathrm{~s}^{-1}\right)$ is the capillary diffusion coefficient, $k_{p}\left(\mathrm{~m}^{2}\right)$ is the permeability of the porous electrode, $M_{w}\left(\mathrm{~kg} \mathrm{~mol}^{-1}\right)$ is the molecular weight of water, $\mu_{w}^{g}, \mu_{w}^{l}$ and $\mu_{g}(\mathrm{~Pa} \mathrm{~s})$ are the viscosity of vapor, liquid water and gas mixture, respectively, $S_{w}^{l}\left(\mathrm{~mol} \mathrm{~m}^{-3} \mathrm{~s}^{-1}\right)$ is the source term of liquid water.

The transport of dissolved water through the membrane/ionomer, under the mechanisms of electroosmotic drag, back diffusion and hydraulic permeation, is described a diffusive approach, leading to the following equation:

$$
\nabla \cdot\left(n_{d} \frac{i_{M}}{F}\right)-\nabla \cdot\left(D_{w-M} \nabla c_{w}^{d}\right)-\nabla \cdot\left(\frac{k_{p, M} c_{w}^{d}}{\mu_{w}} \nabla p\right)=S_{w}^{d}
$$

where $n_{d}$ is the EOD coefficient, $D_{w-M}\left(\mathrm{~m}^{2} \mathrm{~s}^{-1}\right)$ is the diffusivity of dissolved water through the membrane/ionomer, $c_{w}^{d}\left(\mathrm{~mol} \mathrm{~m}^{-3}\right)$ is the concentration of dissolved water, $\mu_{w}(\mathrm{~Pa} \mathrm{~s})$ is the water viscosity, $k_{p, M}\left(\mathrm{~m}^{2}\right)$ is the membrane permeability, $i_{M}\left(\mathrm{~A} \mathrm{~m}^{-2}\right)$ is the ionic current density, $S_{w}^{d}\left(\mathrm{~mol} \mathrm{~m}^{-3} \mathrm{~s}^{-1}\right)$ is the source term, representing the source/sink of dissolved water according to ORR and phase change.

The gradients of the potentials of solid and electrolyte phases lead to the transport of electrons and ions. The current densities of the solid and electrolyte phases are calculated by the following equation:

$$
\begin{aligned}
& i_{s}=-\sigma_{s}^{e f f} \nabla \phi_{s} \\
& i_{M}=-\sigma_{M}^{e f f} \nabla \phi_{M}
\end{aligned}
$$


where $\phi_{s}$ and $\phi_{M}(\mathrm{~V})$ are the potentials of the solid and electrolyte phases, $\sigma_{s}^{\text {eff }}$ and $\sigma_{M}^{\text {eff }}$ are the effective electronic and ionic conductivities, which are determined by the volume fractions of $\mathrm{Pt} / \mathrm{C}$ and ionomer within the catalyst layer of the electrode.

The current density and cell voltage relation is expressed by:

$$
E^{\text {cell }}=E^{O C P}-\eta_{a}-\left|\eta_{c}\right|-i_{M} R_{M}-i_{s} R_{s}
$$

The open-circuit potential (OCP) as a function of temperature is given as follow [39]:

$$
E^{O C P}=-\frac{(\Delta H-T \Delta S)}{n F}+\frac{R T}{n F} \ln \left[\frac{p_{\mathrm{H}_{2}} p_{\mathrm{O}_{2}}^{0.5}}{p_{\mathrm{H}_{2} \mathrm{O}}}\right]
$$

where $\Delta H\left(\mathrm{~J} \mathrm{~mol}^{-1}\right)$ and $\Delta S\left(\mathrm{~J} \mathrm{~mol}^{-1} \mathrm{~K}^{-1}\right)$ are the reaction enthalpy and entropy, respectively.

The reaction kinetics based on the agglomerate assumption is given as follow [40]:

$$
\nabla i_{i}=n F\left(\frac{p_{i}}{H_{i}}\right)^{\gamma}\left[\frac{1}{E_{a g g} k_{\text {agg }}}+\frac{\left(r_{\text {agg }}+\delta\right) \delta}{a_{\text {agg }} r_{\text {agg }} D_{i}^{\text {eff }}}\right]^{-1}
$$

where $E_{a g g}$ is the effectiveness factor, $a_{a g g}$ and $r_{a g g}(\mathrm{~m})$ are the specific area and radius of agglomerate, $\delta(\mathrm{m})$ is the thickness of the ionomer and liquid water films, $D_{i}^{e f f}\left(\mathrm{~m} \mathrm{~s}^{-2}\right)$ is the effective diffusivity inside agglomerate, $H_{i}\left(\mathrm{~Pa} \mathrm{~m}^{3} \mathrm{~mol}^{-1}\right)$ is the Henry's constant, $p_{i}(\mathrm{~Pa})$ is the partial pressure. $\gamma$ is the pressure dependency coefficient, with 0.5 for HOR and 1.0 for ORR. The subscript $i$ if for the anode $(i=a)$ or cathode $(i=c)$.

For the ORR at the cathode, the volumetric current density based on B-V equation could be written as [41]:

$$
i_{c, a g g}=a_{a g g} i_{0, c}^{r e f} \frac{c_{O_{2}, i n}}{c_{O_{2}}^{r e f}}\left[\exp \left(\frac{-\alpha_{c} F \eta_{c}}{R_{g} T}\right)-\exp \left(\frac{\left(1-\alpha_{a}\right) F \eta_{c}}{R_{g} T}\right)\right]
$$

According to Faraday's law we have:

$$
i_{c, a g g}=n F k_{a g g} c_{O_{2}, \text { in }}
$$

Combining Eq. (12) and (13), the rate constant could be expressed as follow: 


$$
k_{a g g}=\frac{a_{a g g} i_{0, c}^{r e f}}{n F c_{O_{2}}^{r e f}}\left[\exp \left(\frac{-\alpha_{c} F \eta_{c}}{R T}\right)-\exp \left(\frac{\left(1-\alpha_{c}\right) F \eta_{c}}{R T}\right)\right]
$$

where $c_{O_{2}}^{r e f}\left(\mathrm{~mol} \mathrm{~m}^{-3}\right)$ is the oxygen reference concentration, $i_{0, c}^{r e f}\left(\mathrm{~A} \mathrm{~cm}^{-2}\right)$ is the reference exchange current density of the ORR, which is correlated by the experimental data with a confidence level of $97.7 \%[41,42]$.

$$
i_{0}^{r e f}=10^{\left(3.507-\frac{4001}{T}\right)}
$$

When the current density is small, the mass transport resistance of reactant gases passing through the ionomer and liquid water films can be neglected. Thus, a simplified B-V equation is used to describe the relation of current density with respect to overpotential.

$$
i=i_{0}\left[\exp \left(\frac{-\alpha_{c} F \eta_{c}}{R T}\right)-\exp \left(\frac{\left(1-\alpha_{c}\right) F \eta_{c}}{R T}\right)\right]
$$

The second term in the bracket could be omitted due to its very small value. After a rearrangement, Eq. (16) becomes:

$$
\eta_{c}=\frac{R T}{\alpha_{c} F} \ln i_{0}-\frac{R T}{\alpha_{c} F} \ln i
$$

The overpotential is defined as the difference of solid phase potential, electrolyte phase potential and the equilibrium potential, showing as follow:

$$
\eta_{c}=\phi^{s}-\phi^{l}-\phi^{e q}
$$

The equilibrium potential is calculated by the theory of thermodynamics, which is zero of the HOR at the anode and equal to the $\mathrm{OCP}$ at the cathode. When the temperature increases, the equilibrium potential decreases. The electrolyte phase potential is very small when the cell voltage is high. As a result, the solid phase potential $\phi^{s}$ is approximately equal to the cell voltage $E$ and the electrolyte phase potential $\phi^{l}$ is close to zero. Therefore, Eq. (17) could be expressed as:

$$
E-\phi^{e q}=\frac{R T}{\alpha_{c} F} \ln i_{0}-\frac{R T}{\alpha_{c} F} \ln i
$$


Plotting $E$ as a function of $\ln i$ gives a straight line, the slope is:

$$
-\frac{R T}{\alpha_{c} F}=\text { slope }
$$

The charge transfer coefficient at the cathode is calculated by the following equation:

$$
\alpha_{c}=-\frac{R T}{\operatorname{slope} \cdot F}
$$

As shown in Fig. 2, the fitted expression of charge transfer coefficient at the cathode as a function of temperature is given as follow:

$$
\alpha_{c}=8.08 \times 10^{-3} T-1.8697
$$

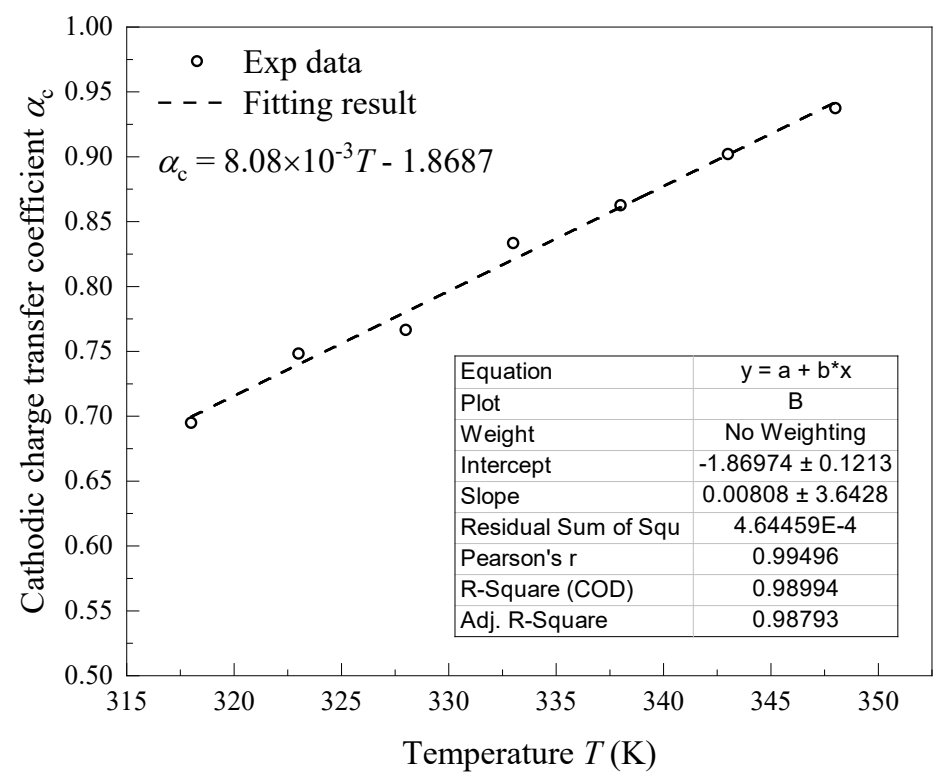

Fig. 2 Fitted charge transfer coefficient at the cathode as a function of temperature. $f=40 \%, m_{\mathrm{Pt}}=0.4 \mathrm{mg} \mathrm{cm}^{-2}$,

$$
I / C \text { ratio }=1.5, L=15 \mathrm{~cm}, R H_{\text {inlet }}=100 \%, \xi_{\mathrm{a}}=1.5, \xi_{\mathrm{c}}=3.0 .
$$

Note that Eq. (19) is only valid for large cell voltages, for which $E$ is close to $\phi^{s}-\phi^{l}$. As a decrease in cell voltages, the current density increases and the polarization becomes more significant, resulting in a remarkable difference of $E$ and $\phi^{s}-\phi^{l}$. The relation of $E$ and $\phi^{s}-\phi^{l}$ at various cell voltages and temperatures are shown in Fig. 3. It is clear that the cell voltage is close to the difference of potentials of the solid and electrolyte phases when the cell voltage and temperature are lower, which could be explained 
by the low activation polarization. When cell voltage and temperature increase, $\phi^{s}-\phi^{l}$ becomes larger than $E$, e. g. at $0.8 \mathrm{~V}$ and $348 \mathrm{~K}, \phi^{s}-\phi^{l}$ is about $1.1 \%$ larger than $E$, and at $0.7 \mathrm{~V}$ the variation is $6.9 \%$. In this work, we regressed the charge transfer coefficient in the cell voltage rang of 0.8 to $0.9 \mathrm{~V}$ with an acceptable accuracy. For a more accurate measurement, cyclic voltammogram is preferred [42].

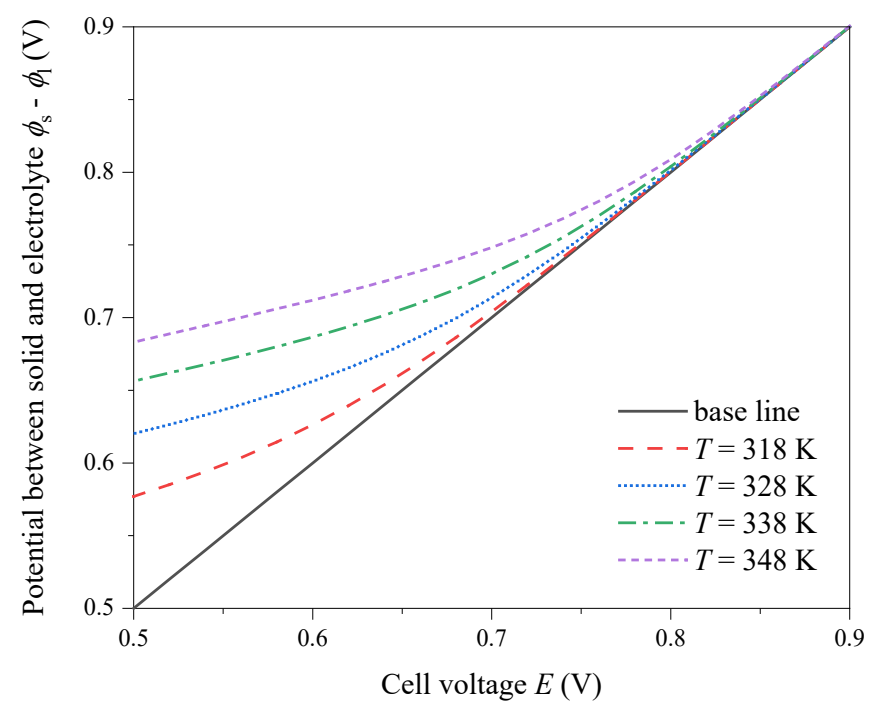

Fig. 3 Relation of $E$ vs. $\phi^{s}-\phi^{l}$ at different temperature and cell voltages

The source terms of the conservation equations of Eqns (1), (3), (5) and (6) are given elsewhere [43-46]. It has been well understood that a variety of parameters used in modelling are affected by platinum loading and temperature. The key parameters as a function of either platinum loading or temperature are given in the following sections.

\subsection{Effect of platinum loading on catalyst layer properties}

Platinum particles are dispersed in carbon black to construct carbon agglomerate. The volume fraction of $\mathrm{Pt} / \mathrm{C}$ is a function of platinum loading.

$$
L_{P t / C}=\frac{m_{P t}}{l_{C L}}\left(\frac{1}{\rho_{P t}}+\frac{1-f}{f} \frac{1}{\rho_{C}}\right)
$$

where $m_{P t}\left(\mathrm{mg} \mathrm{cm}^{-2}\right)$ is the platinum loading, $l_{C L}(\mathrm{~m})$ is the catalyst layer thickness, $\rho_{P t}$ and $\rho_{C}$ are the densities of platinum and carbon, respectively. The platinum to carbon mass ratio, $f$, is given as: 


$$
f=\frac{m_{P t}}{m_{P t}+m_{C}}
$$

where $m_{C}\left(\mathrm{mg} \mathrm{cm}^{-2}\right)$ is the carbon loading.

The catalyst layer porosity is expressed as the following equation.

$$
\varepsilon_{C L}=1-L_{P t / C}-L_{M}-L_{S}
$$

where $L_{S}$ represents the penetration of GDL into CL under a clamping force, $L_{M}$ is the volume fraction of ionomer, which is expressed as:

$$
L_{M}=\frac{m_{M}}{\rho_{M} l_{C L}}
$$

During electrode preparation, the ionomer to carbon mass ratio (I/C) is typically kept as a constant. The volume fraction of ionomer is rearranged as:

$$
L_{M}=\frac{I / C(1-f)}{f} \frac{m_{P t}}{\rho_{M} l_{C L}}
$$

where the $\mathrm{I} / \mathrm{C}$ ratio is defined as:

$$
I / C=\frac{m_{M}}{m_{C}}
$$

The agglomerate density, defined as the number of agglomerate particles per volume of catalyst layer, is given as follow:

$$
N_{a g g}=\frac{3 L_{P t / C}}{4\left(1-\varepsilon_{C L}\right) \pi r_{a g g}^{3}}
$$

where $r_{a g g}(\mathrm{~m})$ is the radius of the agglomerate.

The specific area of carbon agglomerate, defined as the total surface area per volume of the agglomerate, is expressed as follow:

$$
a_{a g g}=\frac{3 m_{P t} A_{s}}{4 \pi l_{C L} N_{a g g} r_{a g g}^{3}}
$$


where $A_{s}\left(\mathrm{~m}^{2} \mathrm{~kg}^{-1}\right)$ is the reaction surface area per unit platinum mass, which is calculated by an empirical equation as follow [47]:

$$
A_{s}=\left(227.79 f^{3}-158.57 f^{2}-201.53 f+159.5\right) \times 10^{3}
$$

The thicknesses of ionomer and liquid water films are calculated using the following equations.

$$
\begin{gathered}
\delta_{M}=r_{a g g}\left[\sqrt[3]{\frac{\left(1-\varepsilon_{C L}\right)\left(1-\varepsilon_{C L}-L_{S}\right)+L_{P t / C} \varepsilon_{C L}(1-\% M)}{L_{P t / C}}}-1\right] \\
\delta_{w}=\sqrt[3]{\left(r_{a g g}+\delta_{M}\right)^{3}+\frac{s \varepsilon_{C L}\left(1-\varepsilon_{C L}\right) r_{a g g}^{3}}{L_{P t / C}}}-\left(r_{a g g}+\delta_{M}\right)
\end{gathered}
$$

where $\% M$ is the volume faction of the primary pores (intra-agglomerate) occupied by ionomer, $s$ is the water saturation, which is defined as the volume fraction of water inside the secondary pores (interagglomerate) of the electrode. More details of catalyst layer properties could be found elsewhere [48]. It is clear that when platinum loading is higher, the CL porosity and the thickness of ionomer and liquid water films decrease, while the agglomerate density and specific area of agglomerate increase.

\subsection{Temperature-dependent transport properties}

The increase in temperature in principle increases the membrane conductivity, oxygen diffusivity through ionomer film, and water migration rate through the membrane. For the oxygen diffusion coefficient through Nafion $^{\circledR}$ ionomer, Marr and Li [39] developed a temperature-dependent expression by fitting the experimental data of Parthasarathy et al [40]. In addition to the effect of temperature, Suzuki et al. [49] reported that the oxygen diffusion coefficient is proportional to the membrane water content according to a power law. Combing the effect of both temperature and water content, an equation is obtained as following [37], which agrees well with the experimental data of Takamura et al. [50].

$$
D_{O_{2}-M}=1.3926 \times 10^{-10} \lambda^{0.708} \exp \left(\frac{T-273.15}{106.65}\right)-1.6461 \times 10^{-10} \lambda^{0.708}+5.2 \times 10^{-10}
$$


The Henry's constant for oxygen solubility in Nafion ${ }^{\circledR}$ ionomer is also a function of temperature and ionomer water content. An equation is given by fitting the results of Suzuki et al. [49] and Nonoyama et al. [51].

$$
H_{O_{2}}=0.11552 \exp \left(14.1+0.0302 \lambda-\frac{666}{T}\right)
$$

The water diffusion coefficient is strongly determined by temperature and membrane water content. The intrinsic water diffusivity is expressed as a function of temperature [52], shown as follow:

$$
D_{w-M}^{0}=1.0 \times 10^{-10} \exp \left[2416\left(\frac{1}{303}-\frac{1}{T}\right)\right]
$$

The ionic conductivity of Nafion ${ }^{\circledR}$ membrane/ionomer is determined by temperature and its water content [52].

$$
\sigma_{M}=\exp \left[1268\left(\frac{1}{303}-\frac{1}{T}\right)\right](0.5139 \lambda-0.326)
$$

\subsection{Boundary conditions}

The membrane/ionomer water content on the GDL-CL interfaces of the anode and cathode are defined as Dirichlet boundaries, expressed by the following equation:

$$
\lambda_{i}=0.043+17.81 \alpha_{w, i}-39.85 \alpha_{w, i}^{2}+36.0 \alpha_{w, i}^{3}
$$

where $\alpha_{w, i}$ is the water activity at the GDL-CL interfaces of the anode and cathode, which is a function of pressure.

$$
\alpha_{w, i}=x_{w, i} \frac{p_{i}}{p_{s a t}}+2 s
$$

The pressure and relative humidity at the inlets of anode and cathode were set to 1.0 atm and $100 \%$, respectively. The temperature at the cathode inlet and outlet were defined as Dirichlet boundaries with a given value at the boundaries. Since counter flow mode was applied, the temperature at the cathode inlet was that at the anode outlet. The concentrations of hydrogen, oxygen, nitrogen and vapor at the inlets were given as follow: 


$$
\begin{gathered}
x_{w, a}^{0}=\frac{p_{s a t} R H_{a}^{0}}{p_{a}}, x_{H_{2}}^{0}=1-x_{w, a}^{0} \\
x_{w, c}^{0}=\frac{p_{s a t} R H_{c}^{0}}{p_{c}}, x_{O_{2}}^{0}=0.21\left(1-x_{w, c}^{0}\right), x_{N_{2}}^{0}=0.79\left(1-x_{w, c}^{0}\right)
\end{gathered}
$$

The vapor saturation pressure with respect to temperature could be expressed by [49]:

$$
\log p_{\text {sat }}=-19.0437+0.1084 T-2.1022 \times 10^{-4} T^{2}+1.4454 \times 10^{-7} T^{3}
$$

When temperature increases, the partial pressure of vapor increases, leading to an increase in the volume fraction of vapor in a gas mixture. According to Eq. (41), the oxygen content is reduced by the increased vapor content, which dilutes the effective oxygen concentration in the gas mixture.

The gas velocities at the inlets are related to their stoichiometric flow ratio shown as follow:

$$
u_{g, a}^{0}=\frac{\xi_{a} R T i^{r e f} A_{M}}{2 F p_{a} x_{H_{2}} A_{c h}}, u_{g, c}^{0}=\frac{\xi_{c} R T i^{r e f} A_{M}}{4 F p_{c} x_{O_{2}} A_{c h}}
$$

where $i^{r e f}\left(\mathrm{~A} \mathrm{~cm}^{-2}\right)$ is the reference current density, $\xi_{a}$ and $\xi_{c}$ are the stoichiometric flow ratio of the anode and cathode, respectively. $A_{M}$ and $A_{c h}\left(\mathrm{~m}^{2}\right)$ are the effective area of the electrode and the cross-sectional area of the channel, respectively. The parameters of the membrane electrode assembly (MEA) and operating conditions are listed in Table 2.

\subsection{Homogeneity of current density}

The normalized variation is used to quantitatively present the homogeneity of current density along the cathode channel - GDL interface, which is expressed as:

$$
S=\frac{s v}{\tilde{i}}
$$

where $\tilde{i}\left(\mathrm{~A} \mathrm{~cm}^{-2}\right)$ is the averaged current density along the length of the interface, $s v$ is the standard variance between the non-uniform spatial current density along the channel - GDL interface and the averaged current density, shown as follow: 


$$
s v=\sqrt{\frac{\sum\left(i_{x}-\tilde{i}\right)^{2}}{n-1}}
$$

\subsection{Numerical solution}

The fully coupled conservation equations were solved by COMSOL Multiphysics 5.3 based on finite element method (FEM). The MUMPS stationary solver was chosen. At the nodes of the developed mesh over the computational domain, the mathematical expressions accounting for various phenomena are numerically solved with the boundary conditions, and then an iterative process is performed until the calculation error is smaller than $1.0 \times 10^{-4}$. A parameter sweep method was used and the cell voltage in the range of $0.9-0.3 \mathrm{~V}$ was employed, so that the polarization curves can be plotted during the simulation.

\section{Experiment}

\subsection{Polarization curves to regress charge transfer coefficient}

Polarization curves at high cell voltages from 0.8 to $0.9 \mathrm{~V}$ were used to regress the temperature-dependent charge transfer coefficient at the cathode. Catalyst layer with uniformly distributed $\mathrm{Pt} / \mathrm{C}$ and ionomer was prepared by $40 \% \mathrm{Pt} / \mathrm{C}$ and ionomer suspension with Pt loading of $0.4 \mathrm{mg} \mathrm{cm}^{-2}$ and ionomer loading of 0.9 $\mathrm{mg} \mathrm{cm}^{-2}$ (I/C ratio of 1.5). During MEA fabrication, a certain amount of de-ionized water was added into Nafion ${ }^{\circledR}$ and well mixed in a glass beaker under stirring, followed by ultra-sonication for 15 mins. The required amount of $\mathrm{Pt} / \mathrm{C}($ Vulcan $\mathrm{XC}-72)$ and isopropanol were added into the above solution to prepare a catalyst ink, which was then placed in ultrasonic bath for a further 30 mins at room temperature. The ink was sprayed evenly onto the surface of GDL using a spray gun (Badger Model $100^{\mathrm{TM}}$ ) fed by $\mathrm{N}_{2}$ as carrying gas. Polytetrafluoroethylene (PTFE) treated commercial carbon papers TGP-H-120 (Toray) were used as GDLs. After ink praying, the carbon paper was heated on a hot plate to maintain the temperature at 80-100 ${ }^{\circ} \mathrm{C}$ for good liquid evaporation. Nafion ${ }^{\circledR}$ solution in di-ionized water was used as binder. Nafion ${ }^{\circledR} 115$ membrane (DuPont) was sandwiched between the cathode and the anode, and then hot pressed for 3 min at a pressure of $500 \mathrm{~kg}$ and temperature of $100{ }^{\circ} \mathrm{C}$. Potentiostatic tests were performed, with the atmospheric pressure and fully humidified gases at the anode and cathode, corresponding to their inlet temperature. The 
gas flow direction is in a counter-flow pattern. Hydrogen stoichiometry of 1.5 and air stoichiometry of 3.0. Polarization curves were recorded during at a scan rate of $10 \mathrm{mV} \mathrm{s}^{-1}$ by employing Autolab (PGSTAT 30, Eco Chemie), subject to several cycles until steady performance was reached.

\subsection{Segmented fuel cell unit manufacturing and testing}

A segmented fuel cell unit, consisting of 5 individual graphite segments, was developed to validate the numerical results. As shown in Fig. 1, the fuel cell fixture included a pair of stainless steel end plates $(250 \times 50 \times 15 \mathrm{~mm})$, polycarbonate frames $(250 \times 50 \times 20 \mathrm{~mm})$, copper current collectors, silicone heating plates, aluminum radiators and gaskets. MEA was sandwiched in between. Five graphite bipolar plates $(30 \times 30 \times 20 \mathrm{~mm})$ were inlaid in the polycarbonate frames and electrically and thermally insulated between adjacent segments. On each graphite plate, five parallel straight channels $(30 \times 2 \times 2 \mathrm{~mm})$ were machined. The rib width was $1 \mathrm{~mm}$ between adjacent channels. On the polycarbonate frames, channels with the same dimensions of that on the graphite bipolar plates were grooved with a length of $10 \mathrm{~mm}$ to connect the channels of each graphite bipolar plate. Therefore, the whole flow channel field area is $190 \mathrm{~mm}$ long and $14 \mathrm{~mm}$ wide. Thermocouples were inserted into the drilled holes on the top of each graphite bipolar plate and placed close to the channels to monitor the local temperature of the channels. Temperature was controlled by the corresponding silicon heating plates and external digital automatic controller with respect to the accuracy of $\pm 0.5^{\circ} \mathrm{C}$. Each heating plate was attached to a fan-shaped aluminum radiator for an improved heat removal on the side of the plate. The radiators were connected to the specialized fans as heat sink, in case enhanced heat transfer was required. The heat between different segments was isolated by the polycarbonate frames with a low thermal conductivity of $0.2 \mathrm{~W} \mathrm{~m}^{-1} \mathrm{~K}^{-1}$. Thus, different segments could be heated up and maintained to their required temperature by adjusting the input power and heat removal rate. The generated current of each segment was collected and measured individually by a copper plate with the identical area of the graphite plates, connected with a pair of current collection pillar screwed on the bottom of each graphite plate. Totally 12 nuts and bolts were used around the segmented fuel cell unit to clamp the electrode membrane assembly (MEA) and ensure the uniform contact resistance. A full length MEA was sandwiched between two silicon gaskets at the anode and cathode, respectively. The catalyst loading was 
set as a graded distribution with larger loading of the segments near the cathode inlet and lower near the outlet. The catalyst ink was sprayed onto the electrode with a $30 \times 15 \mathrm{~mm}^{2}$ surface area of each segment. Since no catalyst was placed between the spaces of the segments, the overall active area for the electrochemical reaction is $22.5 \mathrm{~cm}^{2}$.

The preparation and testing of segmented MEA follow the approaches used for measuring the polarization curves at high cell voltages. A rectangle carbon paper with $190 \mathrm{~mm}$ in length and $15 \mathrm{~mm}$ in width was divided into 5 segments, separated by $10 \mathrm{~mm}$ gaps between adjacent segments. Therefore, the entire carbon paper consists with 5 individual segments with a surface area of $30 \times 15 \mathrm{~mm}^{2}$ of each. Catalyst ink with different Pt loading, varying from 0.3 to $0.5 \mathrm{mg} \mathrm{cm}^{-2}$ was sprayed onto the surface of each segment. The I/C ratio of 3:7 was applied on each segment with various Pt loadings.

Table 1 MEA and operation parameters used in the model

\begin{tabular}{lll}
\hline Parameter & Symbol (unit) & Value \\
\hline GDL thickness & $\delta_{\mathrm{GDL}}$ & 370 \\
GDL porosity & $\varepsilon_{\mathrm{GDL}}$ & 0.6 \\
GDL permeability & $k_{p, \mathrm{GDL}}$ & $3.9 \times 10^{-12}$ \\
GDL conductivity & $\sigma_{\mathrm{GDL}}\left(\mathrm{S} \mathrm{m}^{-1}\right)$ & $2.25 \times 10^{4}$ \\
Contact angle of GDL & $\theta_{\mathrm{GDL}}\left({ }^{\circ}\right)$ & 120 \\
CL thickness & $\delta_{\mathrm{CL}}(\mu \mathrm{m})$ & 15 \\
MPL thickness & $\delta_{\mathrm{MPL}}(\mu \mathrm{m})$ & 20 \\
MPL porosity & $\delta_{\mathrm{MPL}}$ & 0.2 \\
Membrane thickness & $\delta_{\mathrm{M}}(\mu \mathrm{m})$ & 120 \\
Contact angle of MPL & $\theta_{\mathrm{MPL}}\left({ }^{\circ}\right)$ & 150 \\
Platinum to carbon ratio & $f$ & 0.4 \\
Ionomer to carbon ratio & $I / C$ & $3 / 7$ \\
Anode charge transfer coefficient & $\alpha_{\mathrm{a}}$ & 0.5 \\
Relative humidity & $R H$ & 1.0 \\
Anode stoichiometry & $\xi_{a}$ & 1.5 \\
& & \\
\hline
\end{tabular}




\begin{tabular}{llc} 
Cathode stoichiometry & $\xi_{c}$ & 3.0 \\
Channel length & $L_{C h}(\mathrm{~cm})$ & 15 \\
Channel width & $W_{\mathrm{Ch}}(\mathrm{mm})$ & 2.0 \\
Channel depth & $D_{\mathrm{Ch}}(\mathrm{mm})$ & 2.0 \\
Agglomerate radius & $r_{\mathrm{agg}}(\mu \mathrm{m})$ & 0.1 \\
\hline
\end{tabular}

\section{Results and discussions}

\subsection{Charge transfer coefficient}

As shown in Fig. 2, the charge transfer coefficient at the cathode, as a function of temperature, was regressed from the experimental data in Fig. S1 in Supplementary Materials. It is believed that in high cell voltage range, corresponding to low current density, the overall reaction rate is controlled by intrinsic reaction kinetics. The effects of mass and charge transport are negligible [48]. Thus, we choose the current density of the cell in the voltage range of $0.8-0.9 \mathrm{~V}$ to obtain the charge transfer coefficient as a function of operating temperature using Eq. (21). We can see that the relation of $\alpha_{\mathrm{c}}$ and $T$ almost follows a linear relationship, as shown in Fig.2. The R-square around 99\% implies a highly confident linear relation of charge transfer coefficient as a function of temperature. Cathodic charger transfer coefficient has a significantly important impact on the volumetric current density.

\subsection{Model validation}

For model validation, the strategies of platinum loading and operating temperature are categorized into four cases. Note that graded platinum distributions are only for the cathode side. On the anode, platinum loading is $0.2 \mathrm{mg} \mathrm{cm}^{-2}$. In Fig. 4, the segments $\mathrm{S} 1$ to $\mathrm{S} 5$ represent the positions of different segments close to the cathode inlet (S1) and near the cathode outlet (S5), respectively. In all cases, the temperature at the cathode inlet is fixed at $60{ }^{\circ} \mathrm{C}$, which increases towards the cathode outlet at different gradients, leading to the temperature at the cathode outlet of $70{ }^{\circ} \mathrm{C}$ in case 1 and 2 , and $80{ }^{\circ} \mathrm{C}$ in case 3 and 4 . The monotone increasing of temperature is based on the consideration of water buildup along the channel. The generated water moves towards the outlet along with the gas, leading to an increase in higher volume fraction of liquid 
water near the outlet at the cathode. The water saturation pressure is strongly dependent on temperature, which increases when temperature increases, leading to more water existed as vapor. When the elevated temperature is applied towards the outlet, the generated liquid water could be vaporized and the water saturation is reduced. Since the RH is set as $100 \%$ at the inlet, the mole fractions of water and oxygen at the cathode inlet keeps the same for different cases. On the contrary, platinum loading either increases or decreases along the channel. Platinum loading decreases from 0.5 to $0.3 \mathrm{mg} \mathrm{cm}^{-2}$ in case 1 and 3 , and increases from 0.3 to $0.5 \mathrm{mg} \mathrm{cm}^{-2}$ in case 2 and 4 . The average platinum loading along the channel length is fixed to $0.4 \mathrm{mg} \mathrm{cm}^{-2}$.
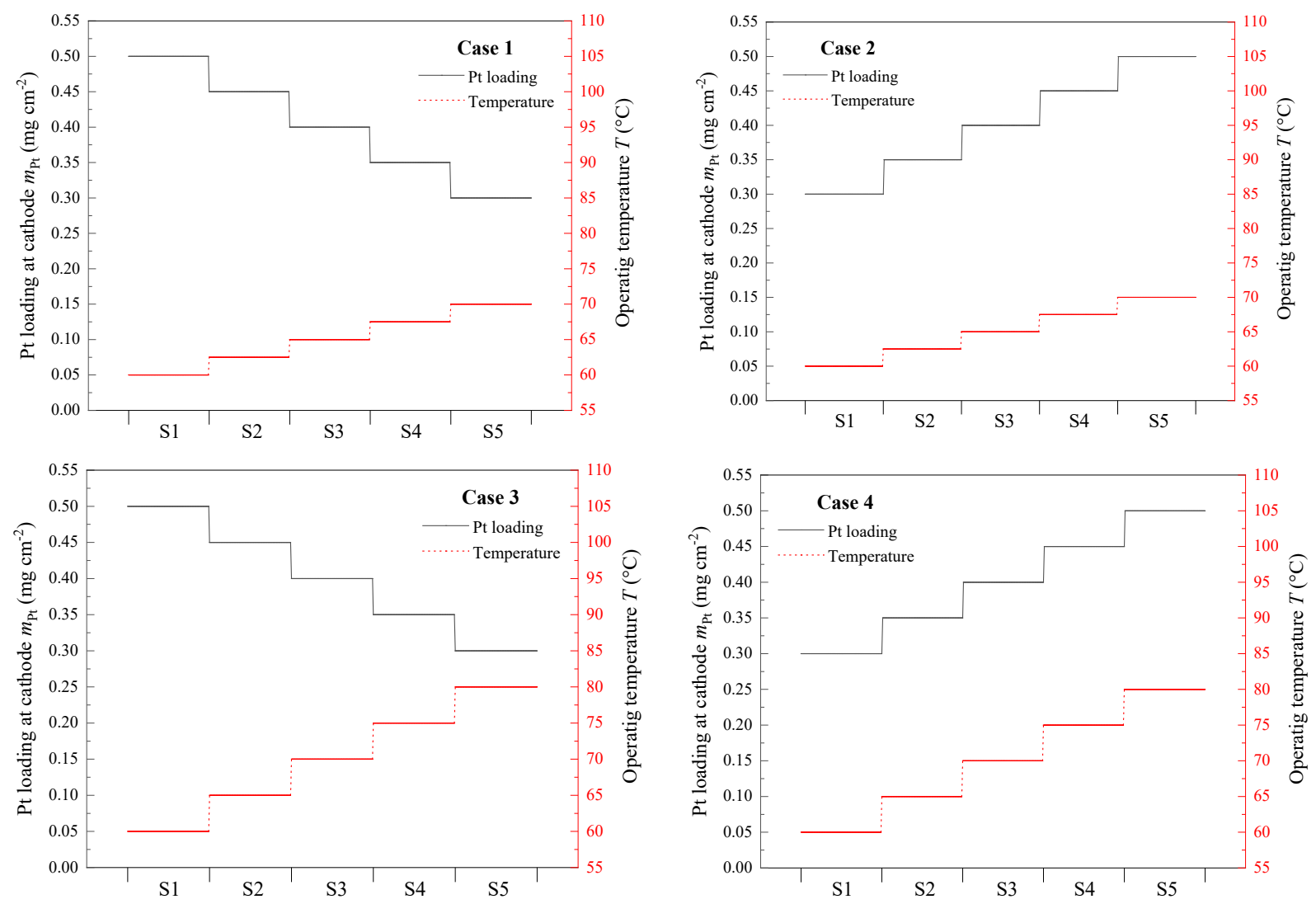

Fig. 4 Operation strategies of Pt loading and temperature for four different cases. The inlet temperature at the cathode is fixed at $60^{\circ} \mathrm{C}$.

The polarization curves of different segments operated in various cases are measured as shown in Fig. 5. It is seen that $\mathrm{S} 1$, the segment close to the cathode inlet, shows the best performance in case 1 and 3 , which can be explained by the higher platinum loading of this segment. Although segments 1 to 3 achieved similar 
polarization curves in case 1 and 3, a sharp drop of the current density of segment 4 and 5 are observed in case 3 . Since the temperature gradient in case 3 is larger than that in case 1 , the higher operating temperature near the cathode outlet is achieved in case 3, which leads to a lower membrane/ionomer water content and a higher volume fraction of vapor due to the increased saturation pressure of water at elevated temperature. In this case, the proton transport resistance increases and the oxygen volume fraction of the gas mixture is diluted by the vapor when it flows towards the cathode outlet, leading to a drop of current density in this region. Similar polarization curves are found in case 2 and 4, in which segments S1 to S3 shows the same increasing trends when both platinum loading and temperature are increasing along the gas flow direction. However, when temperature increases at a large gradient, the positive effect of increased platinum loading and temperature is traded off by the negative effect of the decreased membrane/ionomer water content and diluted oxygen volume fraction. The temperature gradient in case 4 (from 60 to $80^{\circ} \mathrm{C}$ ) is larger than that in case 2 (from 60 to $70^{\circ} \mathrm{C}$ ), the membrane/ionomer water content in segments $\mathrm{S} 4$ and $\mathrm{S} 5$ in case 4 is much lower than that in case 2, as shown in Fig. 6. Thus, the cell performance of S4 and S5 in case 4 is worse than that in case 2 . 

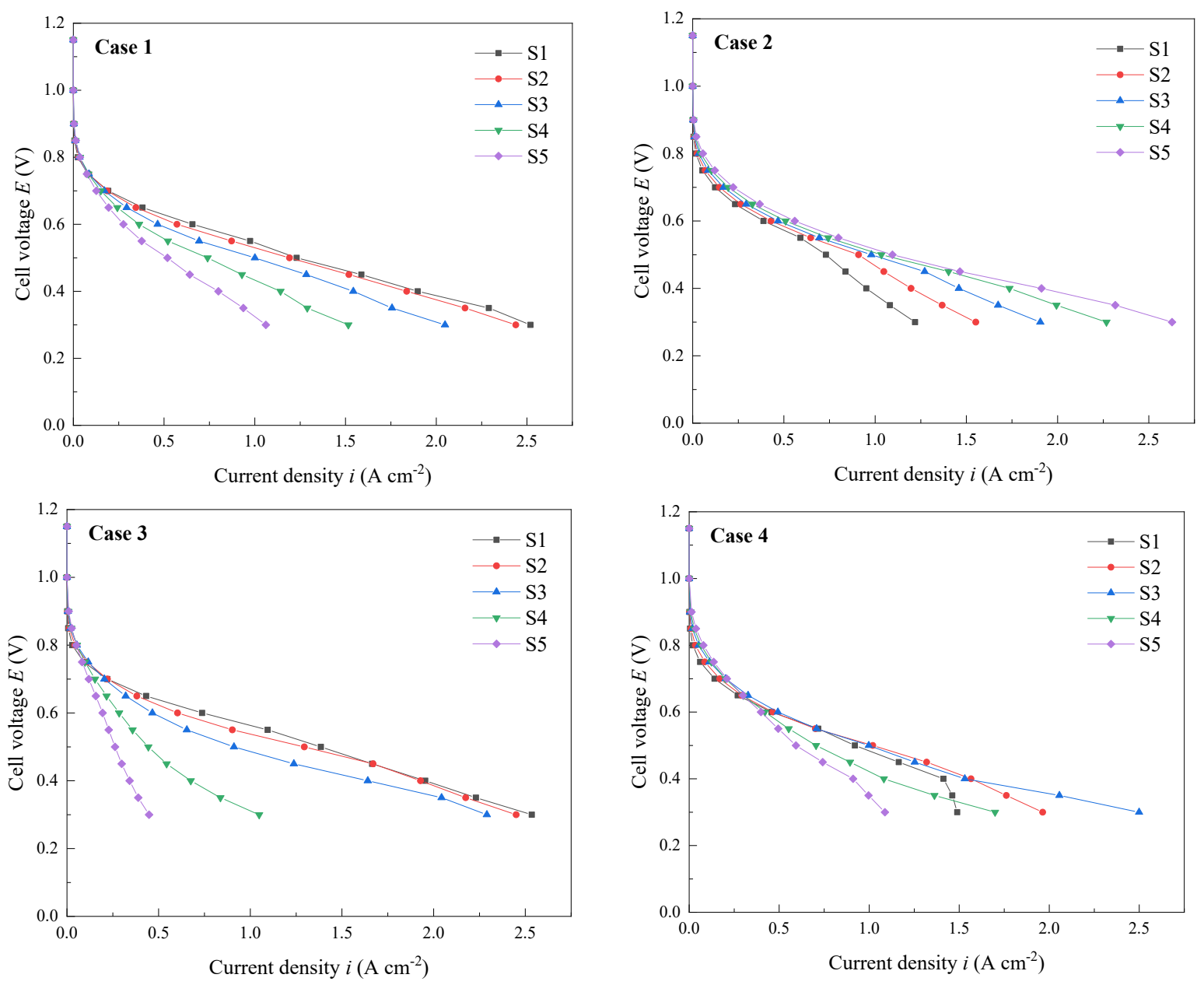

Fig. 5 Polarization curves of different segments in different cases. $100 \%$ relative humidity is applied with respect to the inlet temperature, $60^{\circ} \mathrm{C}$ for the cathode and $70,80^{\circ} \mathrm{C}$ for the anode. $L=15 \mathrm{~cm}, \xi_{\mathrm{a}}=1.5, \xi_{\mathrm{c}}=3.0$. 

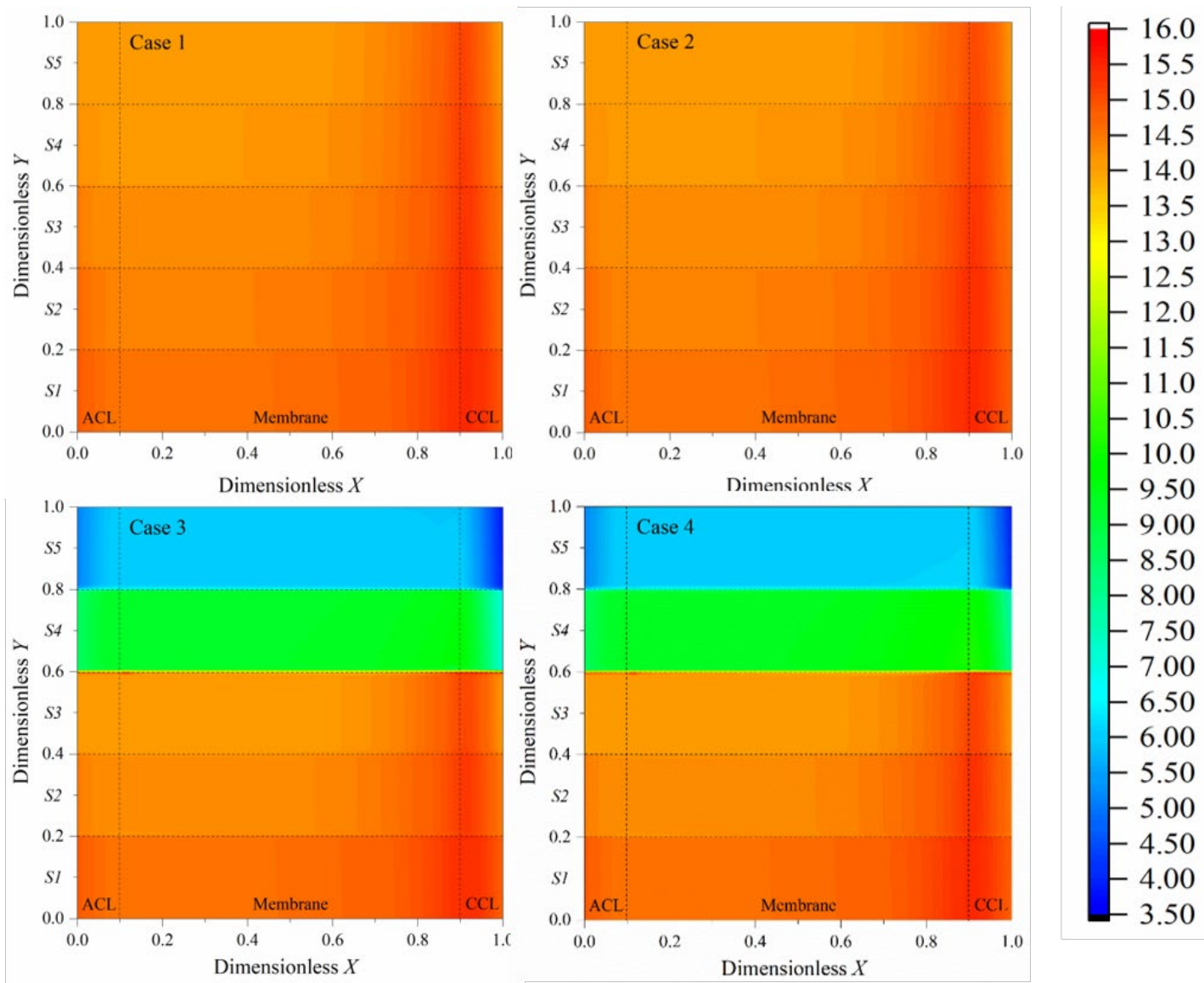

Fig. 6 Membrane/ionomer water content at cell voltage of $0.3 \mathrm{~V}$ of case 1 to $4 . X=0$-GDL-CL interface at the anode, $X=1-$ GDL-CL interface at the cathode, $Y=0$ - cathode inlet, $Y=1-$ cathode outlet. $L=15 \mathrm{~cm}, R H_{\text {inlet }}=$

$$
100 \%, \xi_{\mathrm{a}}=1.5, \xi_{\mathrm{c}}=3.0
$$

The modelling results and experimental data for cell voltage of 0.3 and $0.6 \mathrm{~V}$ were compared in Fig. 7. At the first glance, the modelling results agree well with the experimental data and the operating strategies in case 2 and 4 result in relative uniform current density distributions at $0.6 \mathrm{~V}$. The current densities for other cases are inhomogeneous, particularly for $0.3 \mathrm{~V}$, with the normalized standard variance of current density of $35.5 \%, 56.8 \%, 94.9 \%$ and $53.6 \%$ of case 1 to 4 , respectively. The decrease in current density of the segments from the cathode inlet to the outlet is due to the decrease in platinum loading. When the temperature increasing gradient is small, e. g. from 60 to $70{ }^{\circ} \mathrm{C}$, the increase in platinum loading increases the current density towards the cathode outlet. However, when a large temperature gradient is applied, the decrease in current density is more significant in case 3. On the contrary, when platinum loading increases 
towards the cathode outlet in case 4 , the temperature increment between 60 to $80{ }^{\circ} \mathrm{C}$ initially improves the current density of segments S1 to S3, then declines the current density of segments S4 and S5.
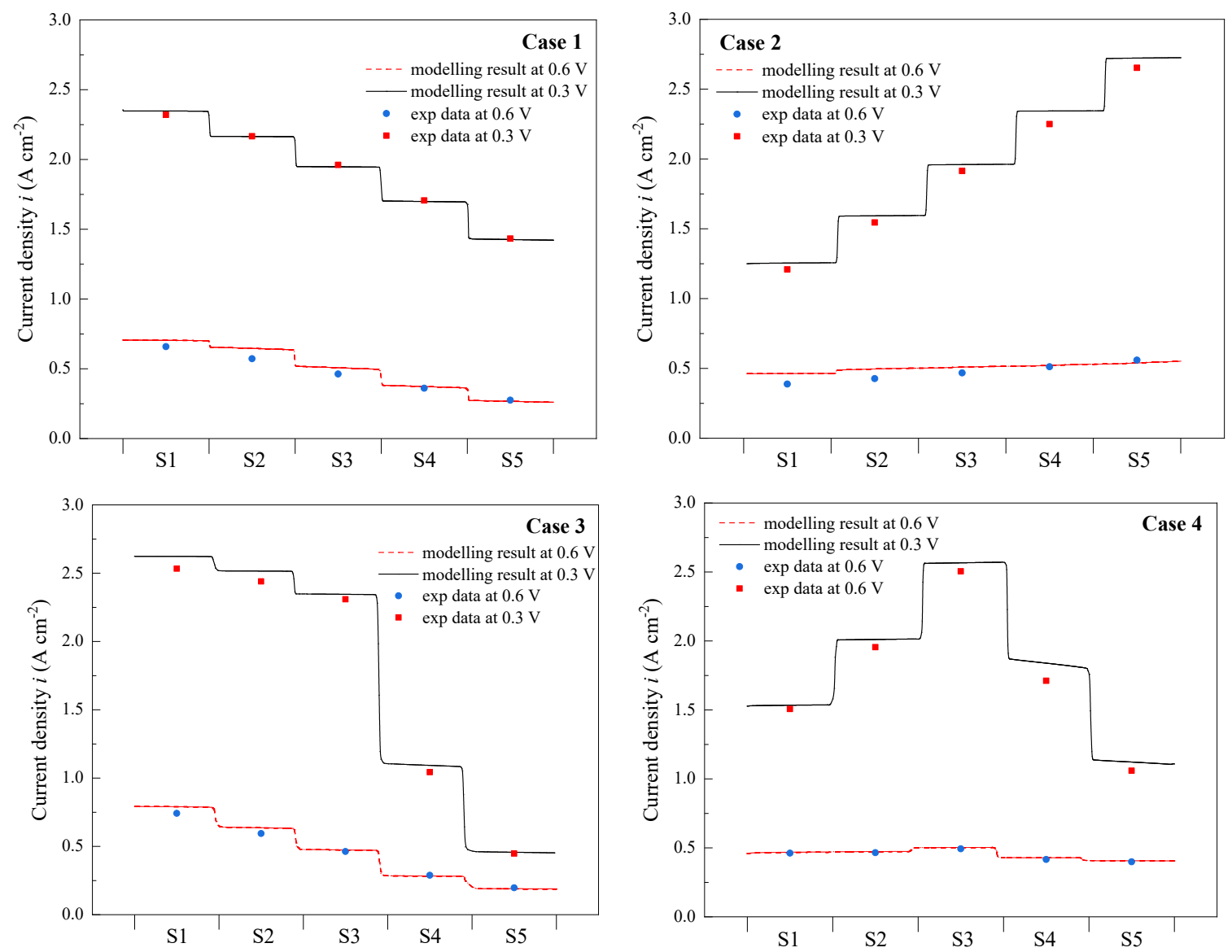

Fig. 7 Current densities at different segments of fuel cells at cell voltage of 0.6 and 0.3 V. $100 \%$ relative humidity is applied with respect to the inlet temperature, $60{ }^{\circ} \mathrm{C}$ for the cathode and $70,80^{\circ} \mathrm{C}$ for the anode. $L=15 \mathrm{~cm}, \xi_{\mathrm{a}}=1.5$, $\xi_{\mathrm{c}}=3.0$.

The overall polarization curves are obtained by averaging the polarization curves of different segments with respect to the total active area. As shown in Fig. 8, operating strategies in cases 1 and 2 improve the current density by $12.6 \%$ at $0.3 \mathrm{~V}$ in comparison with the uniform distributions of platinum loading and temperature, in which the platinum loading and temperature are equal to the average platinum loading and temperature of case 1 and 2. The predicted polarization curves of cases 1 and 2 are almost overlapped, indicating a negligible effect of the profiles of platinum loadings as long as the average platinum loading keeps the same. Case 4 achieves a slight better performance than case 3 since higher platinum loading is 
implemented near the cathode outlet. However, the predicted cell performance is worse than the case with uniformly distributed platinum loading and temperature, which could be explained by the increased proton transport resistance and diluted oxygen in these operating strategies.

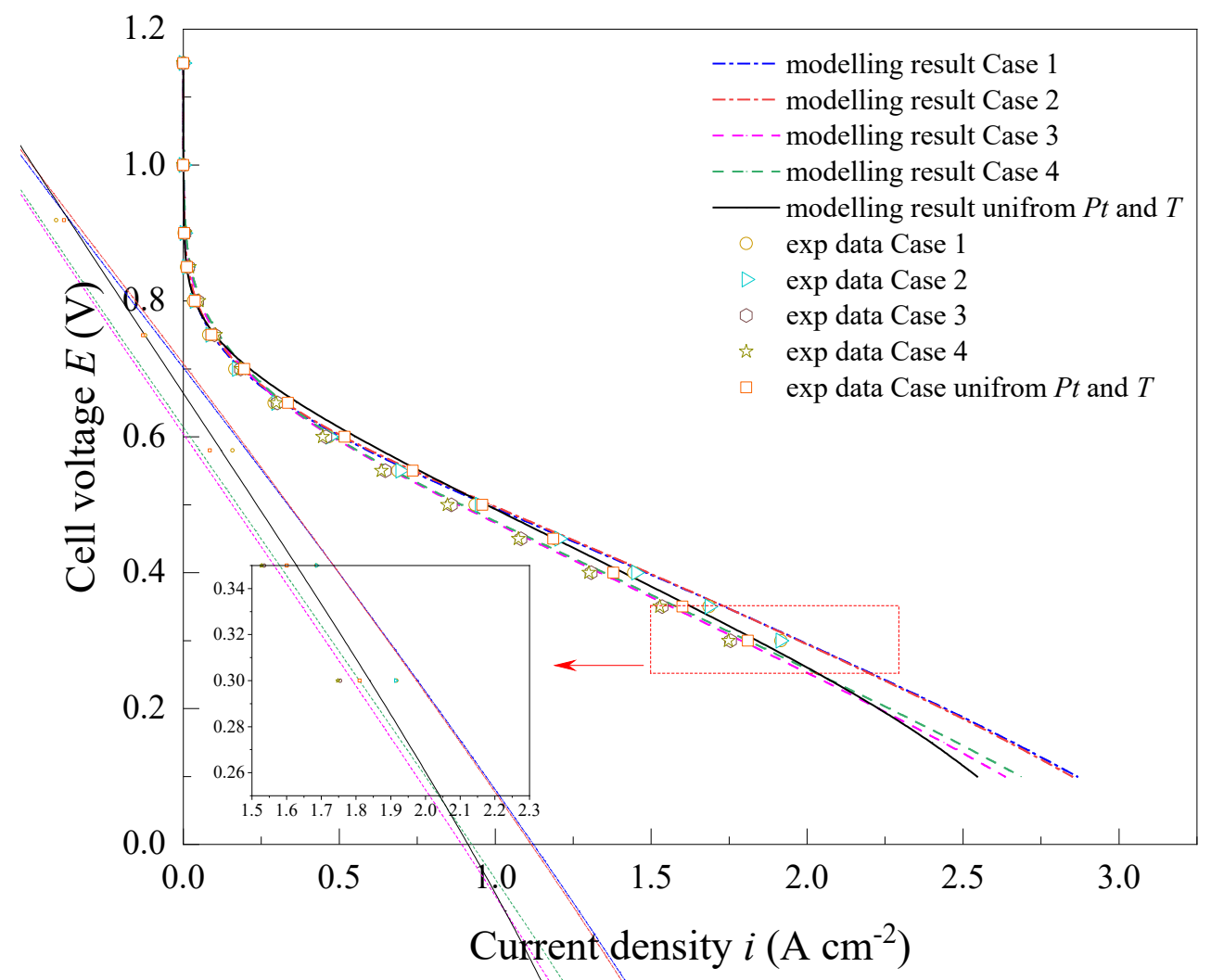

Fig. 8 Averaged polarization curves of different cases. $m_{\mathrm{Pt}}=0.4 \mathrm{mg} \mathrm{cm}^{-2}$ and $T=65^{\circ} \mathrm{C}$ of the uniform platinum loading and operating temperate case. $L=15 \mathrm{~cm}, R H_{\text {inlet }}=100 \%, \xi_{\mathrm{a}}=1.5, \xi_{\mathrm{c}}=3.0$.

Along the gas flow direction within the cathode channel, the increase in temperature leads to an increase in saturation pressure of vapor and a decreases in relative humidity along the GDL-CL interface. In other words, the membrane/ionomer water content at the GDL-CL interface becomes lower towards the cathode outlet. When larger temperature gradient is applied, the membrane and ionomer near the cathode outlet are drier. As an increase in current density, the EOD takes water molecules to the cathode side. When temperature gradient is smaller, e. g from 60 to $70{ }^{\circ} \mathrm{C}$ in cases 1 and 2 , the membrane and ionomer could be hydrated by the humidified gas at the anode side. Thus, as shown in Fig. 6, the lowest water content maintains around 13 at $0.3 \mathrm{~V}$ in case 1 and 2 . However, when larger temperature gradient is applied, e. g. 
from 60 to $80{ }^{\circ} \mathrm{C}$ in case 3 and 4 , the humidified gas at the anode side cannot maintain the hydration of the membrane and ionomer, leading to the lowest membrane/ionomer water content around 3.5 near the cathode outlet. The significantly decreased water content results in an increase in proton transport resistance, then a decline of current density of the segments near the cathode outlet. Taking segments S4 and S5 as examples, in case 3 these two segments show much lower performance than those in case 1, as shown in Fig. 5. Although the performance of segment S3 in case 3 is improved compared with that in case 1, the overall performance is declined due to the drying-out of the membrane and ionomer of segments S4 and S5. The situation in case 4 is similar to that in case 3, the worst cell performance is observed in segments S4 and S5 owing to the low membrane/water content.

\subsection{Individual effect of platinum loading and operating temperature}

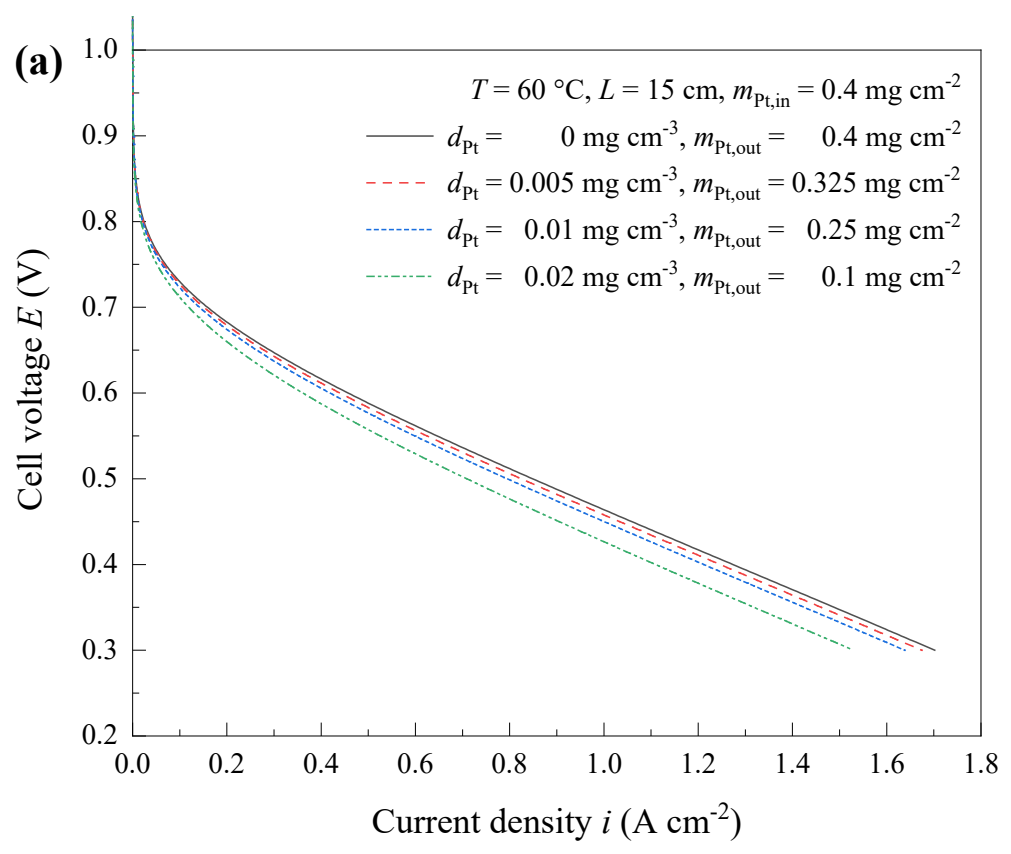




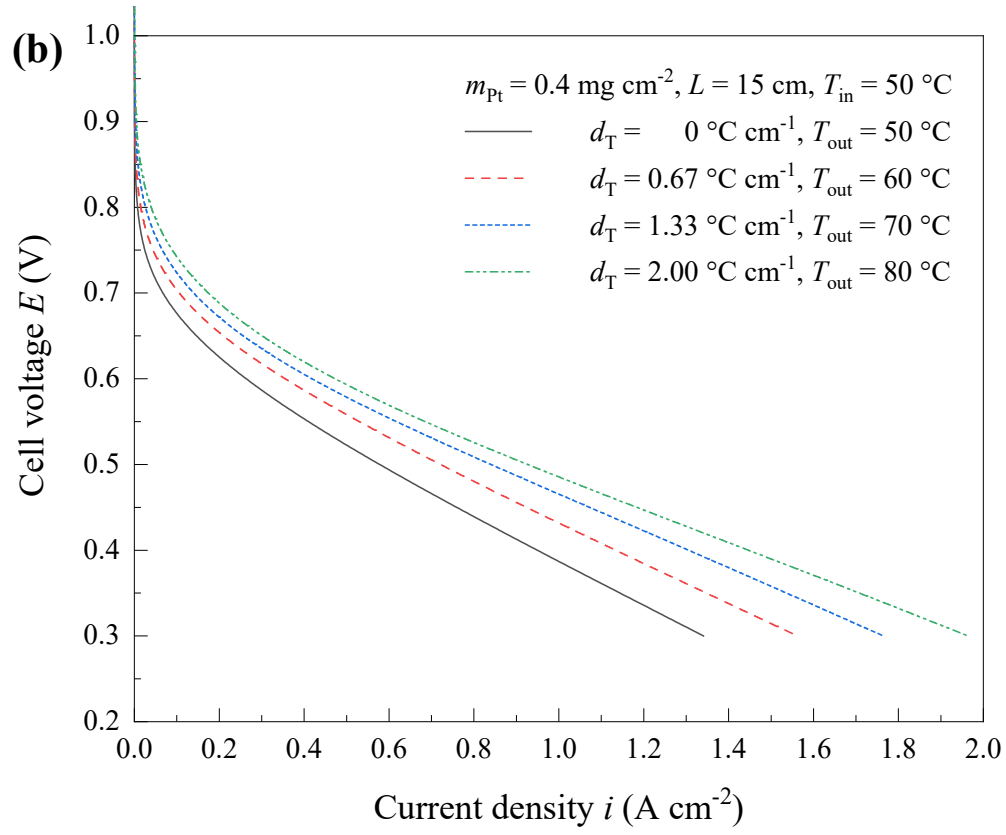

Fig. 9 The individual effect of (a) Pt loading and (b) operating temperature on cell performance. $L=15 \mathrm{~cm}, \mathrm{RH}_{\text {inlet }}=$

$$
100 \%, \xi_{\mathrm{a}}=1.5, \xi_{\mathrm{c}}=3.0 .
$$

The individual effect of platinum loading and operating temperature are shown in Fig. 9 (a) and (b), respectively. When the temperature is fixed at $60^{\circ} \mathrm{C}$ and platinum loading at the inlet is constrained to 0.4 $\mathrm{mg} \mathrm{cm}{ }^{-2}$, the decrease in platinum loading towards the cathode outlet decreases the cell performance as can be seen in Fig. 9 (a). Larger decreasing gradients lead to more significant decrease in current density. It is clear in Fig. 9 (b) that maintaining the platinum loading at $0.4 \mathrm{mg} \mathrm{cm}^{-2}$ and operating temperature at the cathode inlet at $50{ }^{\circ} \mathrm{C}$, the predicted current density increases from 1.34 to $1.96 \mathrm{~A} \mathrm{~cm}^{-2}$ at $0.3 \mathrm{~V}$, when the temperature at cathode outlet increases from 50 to $80^{\circ} \mathrm{C}$. When the profile of platinum loading is reversed, e. g. increasing from a certain value to $0.4 \mathrm{mg} \mathrm{cm}^{-2}$ from the inlet to outlet at the cathode. At the uniform temperature of $60{ }^{\circ} \mathrm{C}$, the cell performance (not shown here) is almost identical to that in Fig. 9 (a), indicating that the increasing or decreasing of platinum loading has almost no effect on the cell performance when the average platinum loadings are identical. The effect of opposite platinum loading profiles becomes more pronounced when the temperature gradient is larger, as confirmed in Fig. 8. Generally, the profiles of platinum loading affect the uniformity of current density more than the overall cell performance. Higher 
platinum loading and operating temperature are beneficial to the cell performance. Both platinum loading and operating temperature have considerable impact on the cell performance. However, individually change of platinum loading and temperature lead to serious inhomogeneity of current density along the gas flow direction, as indicated in Fig. 10.
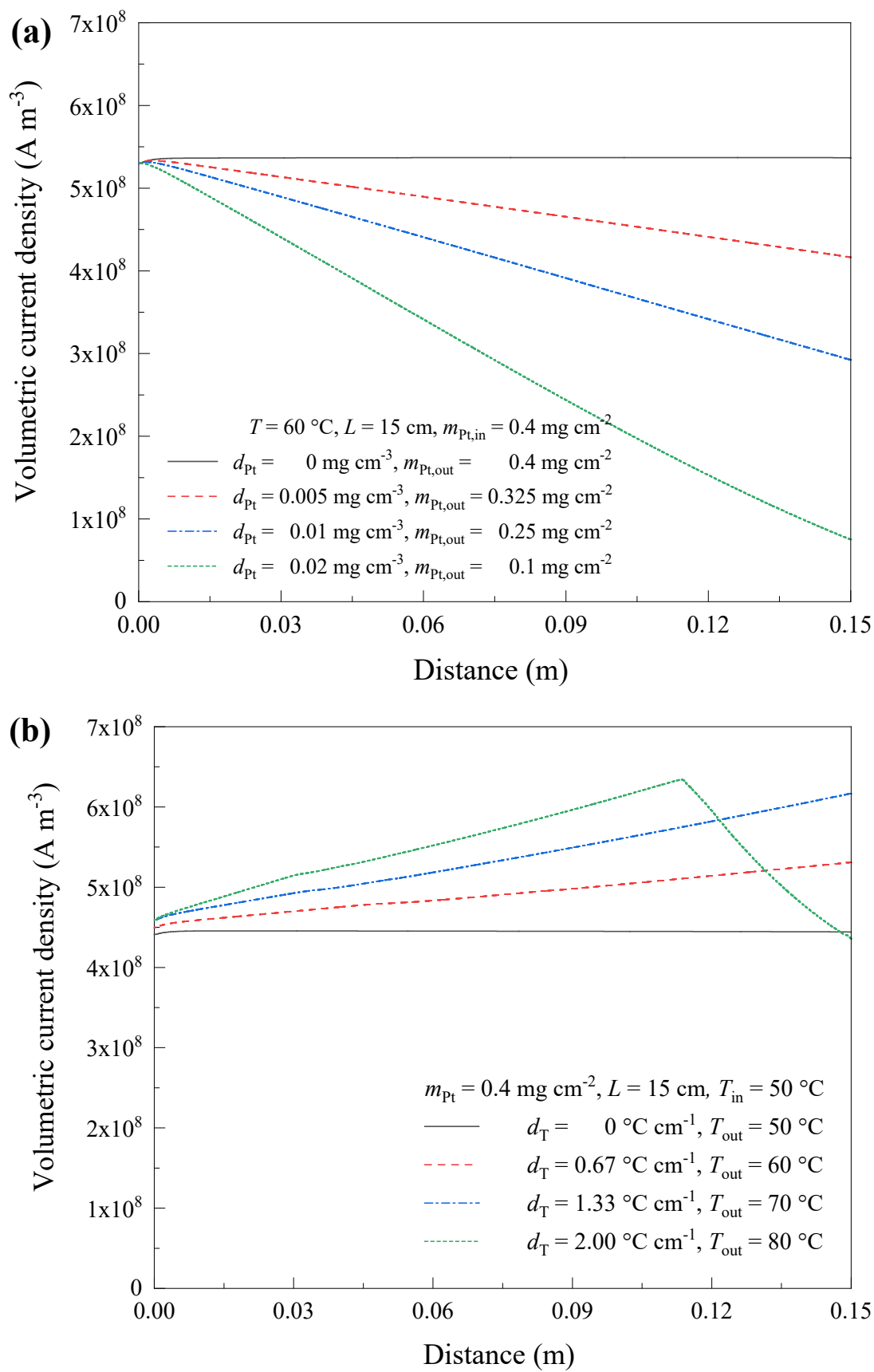

Fig. 10 The individual effect of (a) Pt loading and (b) operating temperature on current density distributions. $L=15$ $\mathrm{cm}, R H_{\text {inlet }}=100 \%, \xi_{\mathrm{a}}=1.5, \xi_{\mathrm{c}}=3.0, E^{\mathrm{cell}}=0.3 \mathrm{~V}$. 
The volumetric current densities at the GDL-channel interface of the cathode are used to present the homogeneity of current density. In Fig. 10 (a), the linear decrease in platinum loading leads to a nearly linear decrease of volumetric current density towards the cathode outlet. In Fig. 10 (b), the linear increase in operating temperature along the gas flow direction at the cathode, in comparison with the effect of platinum loading, results in a nonlinear increase in volumetric current density. The initial increase in temperature from 50 to $70{ }^{\circ} \mathrm{C}$ improves the current density along the GDL-channel interface. However, the further increase in temperature to $80{ }^{\circ} \mathrm{C}$ leads to a volcanic shape of the current density profile. The sharp drop of current density near the outlet is explained by two reasons: firstly, the starvation of oxygen due to the increased fraction of vapor at elevated temperature and secondly, the lower membrane/water content after $12 \mathrm{~cm}$ of the channel length towards the cathode outlet. It is understood that the water carrying capacity (WCC) of the gas mixture increases when temperature increases due to the promoted saturation pressure of vapor. A further increase in temperature may deteriorate cell performance if the relative humidity at the inlet is high [32].
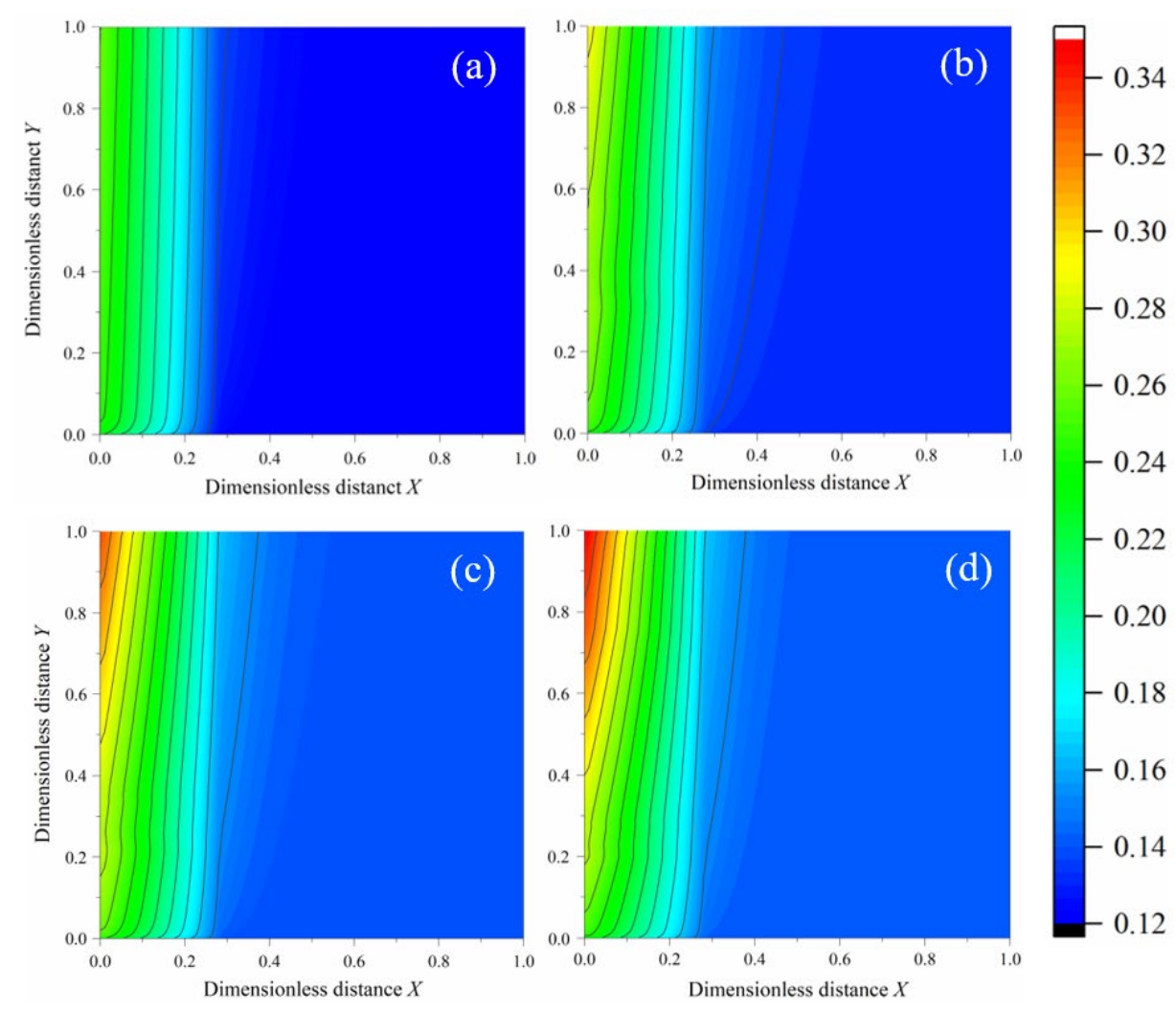
Fig. 11 Mole fraction of vapor in gas mixture at the cathode with different temperature gradients. (a) $T_{\text {out }}=50{ }^{\circ} \mathrm{C}$; (b) $T_{\text {out }}=60^{\circ} \mathrm{C}$; (c) $T_{\text {out }}=70{ }^{\circ} \mathrm{C}$; (d) $T_{\text {out }}=80{ }^{\circ} \mathrm{C} ; X=0-$ membrane $-\mathrm{CL}$ interface, $X=1-$ channel outer boundary, $Y=$ 0 - cathode inlet, $Y=1$ - cathode outlet, $T_{\text {in }}=50^{\circ} \mathrm{C}$ for all cases, $L=15 \mathrm{~cm}, R H_{\text {inlet }}=100 \%, \xi_{\mathrm{a}}=1.5, \xi_{\mathrm{c}}=3.0, E^{\text {cell }}=$ $0.3 \mathrm{~V}$.

The mole fractions of water vapor in the gas mixture at the cathode with different inlet and out temperatures are shown in Fig. 11. The maximum mole fraction of water vapor is observed at the membrane - CL interface at the cathode outlet. It increases from 0.257 to 0.346 , corresponding to a $34.6 \%$ increment, when the temperature at the cathode outlet increases from 50 to $80^{\circ} \mathrm{C}$, which indicates an increase in water carrying capacity of the gas. Considering the electrochemical consumption, the minimum oxygen mole fraction then decreases from 0.098 to 0.047 at $0.3 \mathrm{~V}$ when the temperature at the cathode outlet increases from 50 to $80^{\circ} \mathrm{C}$. The low oxygen concentration may lead to starvation of reactant near the cathode outlet. Thus, the current density decreases in this region.
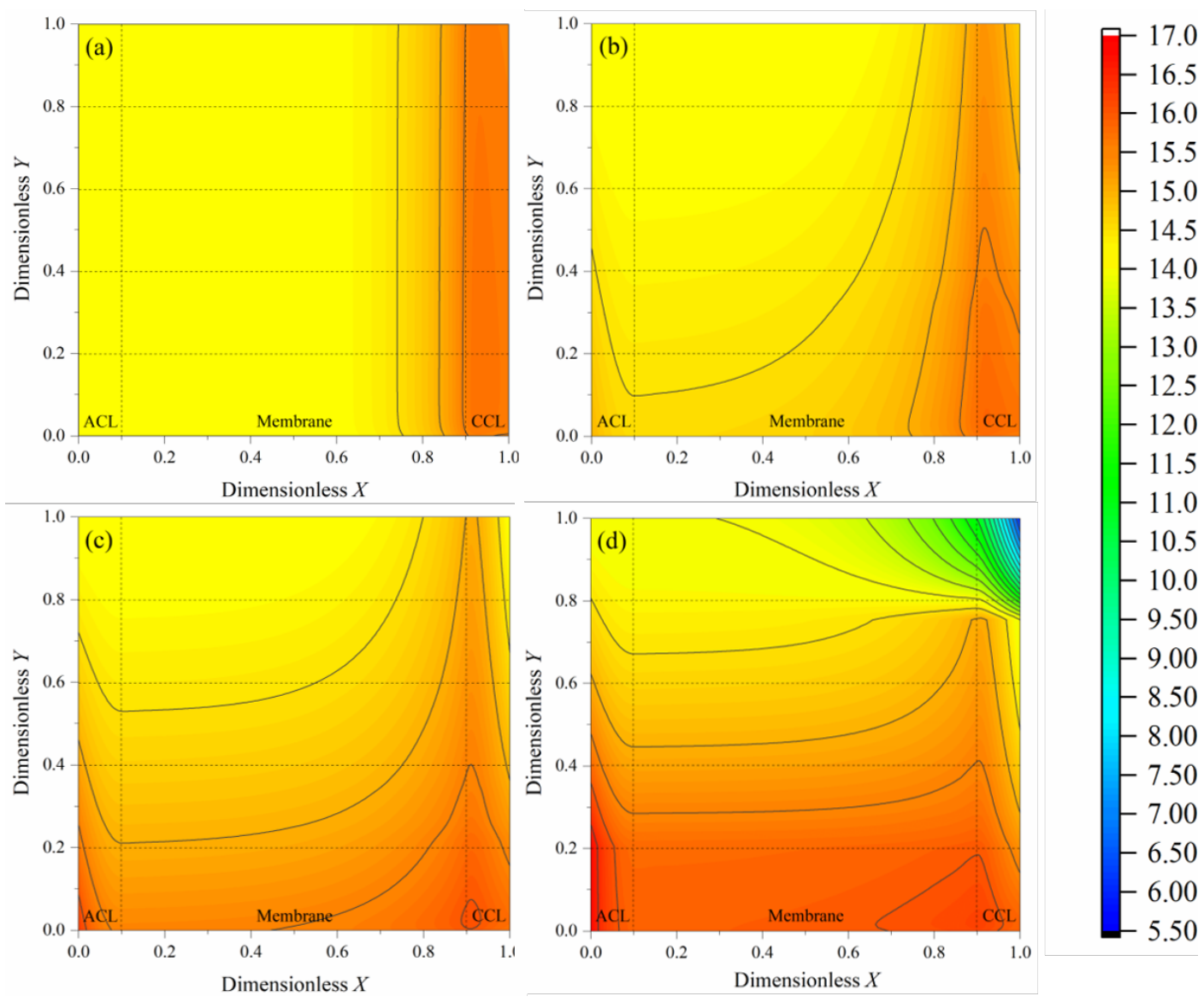
Fig. 12 Membrane/ionomer water content profiles with different temperature gradients. (a) $T_{\text {out }}=50{ }^{\circ} \mathrm{C}$; (b) $T_{\text {out }}=60$ ${ }^{\circ} \mathrm{C}$; (c) $T_{\text {out }}=70{ }^{\circ} \mathrm{C}$; (d) $T_{\text {out }}=80{ }^{\circ} \mathrm{C} ; X=0-$ GDL-CL interface at the anode, $X=1-$ GDL-CL interface at the cathode, $Y=0$ - cathode inlet, $Y=1$ - cathode outlet, $T_{\text {in }}=50{ }^{\circ} \mathrm{C}$ for all cases, $L=15 \mathrm{~cm}, R H_{\text {inlet }}=100 \%, \xi_{\mathrm{a}}=1.5, \xi_{\mathrm{c}}=3.0$, $E^{\mathrm{cell}}=0.3 \mathrm{~V}$.

The profiles of membrane/ionomer water content operated at different inlet and out temperatures are shown in Fig. 12. Since non-uniform temperature profile is applied, the gas flow through the channel towards a higher temperature makes the initially $100 \%$ humidified gas not full saturated, owing to the increase in saturation pressure of vapor. The membrane and ionomer near the cathode outlet dehydrate. The temperature profile is opposite at the anode side, the gas in the anode channel is fully saturated by water until the amount of water loss due to EOD becomes larger than the water supply from inlet gas. At smaller temperature gradients, the membrane and ionomer maintain a relative high level of water content. When temperature gradient becomes larger, the relative humidity in the high temperature region becomes lower. The EOD is not sufficient to hydrate the membrane and ionomer at the cathode side, leading to a dehydration of membrane and ionomer near the cathode outlet.

\subsection{The synergetic effect to platinum loading and operating temperature}

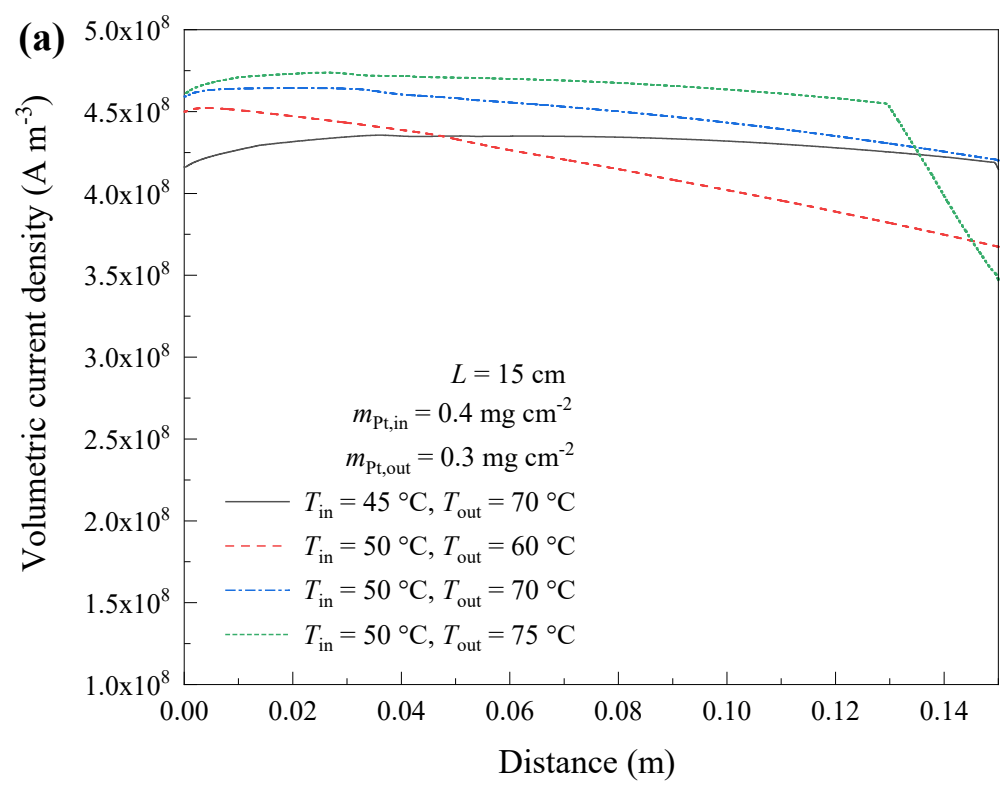




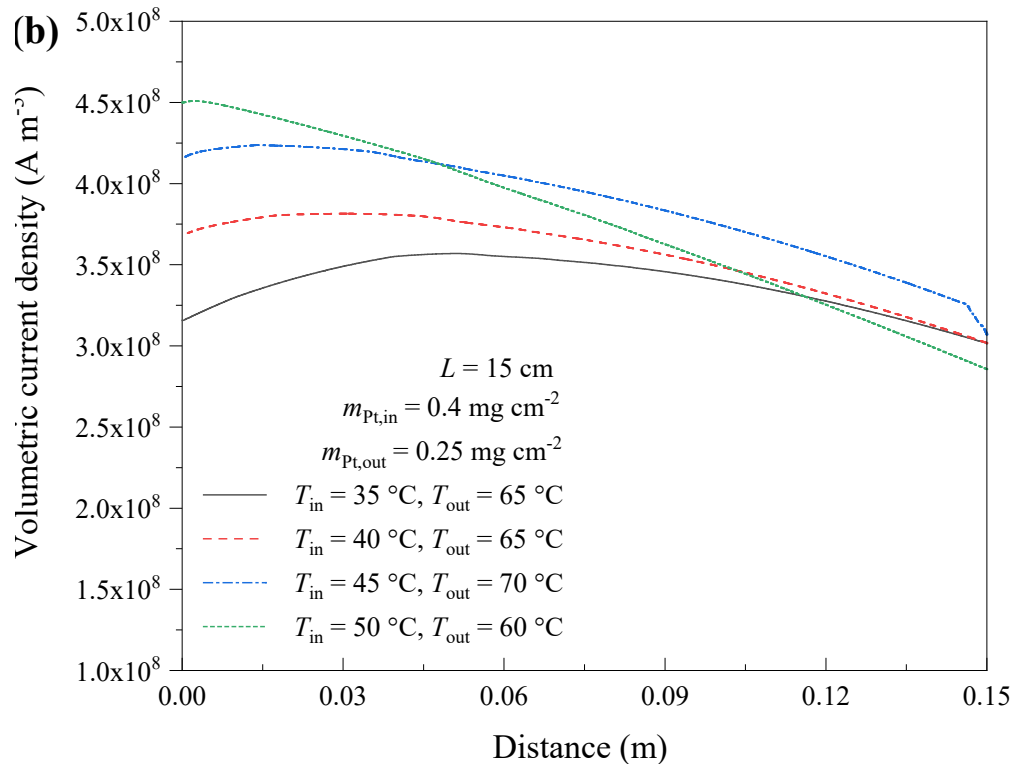

Fig. 13 The synergetic effect of Pt loading and operating temperature on current density distributions. Pt loadings are $0.4 \mathrm{mg} \mathrm{cm}^{-2}$ at cathode inlet and (a) $0.3 \mathrm{mg} \mathrm{cm}^{-2}$; (b) $0.25 \mathrm{mg} \mathrm{cm}^{-2}$ at cathode outlet. $L=15 \mathrm{~cm}, \mathrm{RH}_{\text {inlet }}=100 \%, \xi_{\mathrm{a}}=$ $1.5, \xi_{\mathrm{c}}=3.0, E^{\mathrm{cell}}=0.3 \mathrm{~V}$.

The synergetic effect of platinum loading and temperature on current density distributions at $0.3 \mathrm{~V}$, with respect to different gradients of platinum loading and temperature, are shown in Fig. 13. The platinum loading decreases from 0.4 to $0.3 \mathrm{mg} \mathrm{cm}^{-2}$ in case (a) and from 0.4 to $0.25 \mathrm{mg} \mathrm{cm}^{-2}$ in case (b) towards the cathode outlet. It is found that a larger temperature gradient leads to a sharp decrease of current density along the gas flow direction. To maintain the relative uniform current density along the channel - GDL interface, the optimal temperature gradient varies for different platinum loading gradients. For the smaller platinum loading gradient in case (a), the most uniform current density distribution is achieved when the operating temperature increase from 45 to $70{ }^{\circ} \mathrm{C}$. For the larger platinum loading gradient in case (b), the optimal temperature is from 35 to $65^{\circ} \mathrm{C}$. To guarantee a relative uniform distribution of the in-plane current density, the optimal temperature gradients may not achieve the best performance of the cell. The predicted cell performance can be found in Fig. S2 in Supplementary materials. The cell performance is proportional to the average operating temperature until the effects of membrane/ionomer dehydration and oxygen dilution become pronounced at around $80{ }^{\circ} \mathrm{C}$. We can conclude that the homogeneity of current density distribution is at the cost of the sacrifice of cell performance. The comparison of inhomogeneous and 
uniform profiles of platinum loading and temperature are summarized in Table 2. The normalized variation of current density along the channel - GDL interface is used to represent the homogeneity of current density. Smaller normalized variation means more uniform distribution. Two uniform cases are proposed, one with both the platinum loading and temperature averaged between the inlet and outlet, and the other with the platinum loading and operating temperature at the inlet, at the cathode. The results imply that, in the former uniform case, when the Pt loading and temperature are the averaged value of the graded cases, the improvement of current density at $0.3 \mathrm{~V}$ are very little. In addition, the cell performance is declined by $10 \%$ at $0.6 \mathrm{~V}$. On the contrary, in the later uniform case, the graded design improves the cell performance from 10 to $45 \%$ at $0.3 \mathrm{~V}$ and from 20 to $260 \%$ at $0.6 \mathrm{~V}$, depending on the gradients of platinum loading and operating temperature. Although the platinum loading decreases from the inlet towards the outlet, the increase in temperature compensates the current density loss due to decreased platinum loading and improves the cell performance in comparison with the uniform cases. More importantly, the inhomogeneous platinum loading distribution save the use of platinum as the ORR catalyst by 12.5 and $18.8 \%$ for two different platinum gradients. Although higher cell performance is obtained at larger temperature gradients, the normalized variation of current density becomes larger, making the worse homogeneity of current density, e. g. in case (a), the normalized standard variance of current density at $0.6 \mathrm{~V}$ increases from $6 \%$ to $22 \%$ when the temperature at the cathode outlet increases from 60 to $75^{\circ} \mathrm{C}$.

It is anticipated that the liquid water content inside the void space of the porous electrodes and channels is reduced by the higher temperature near the area of the bipolar plate channel outlet. The profiles of water saturation at the cell voltage of $0.3 \mathrm{~V}$ with different temperature gradients are shown in Fig. 14. The platinum loading decreasing from 0.4 to $0.3 \mathrm{mg} \mathrm{cm}^{-2}$ is selected. Due to the decrease in platinum loading, the water saturation along the gas flow direction decreases. When both the operating temperature of the cathode inlet and outlet is fixed at $60{ }^{\circ} \mathrm{C}$, the water saturation near the cathode outlet is about $12 \%$. However, for other cases with various temperature gradients, the water saturation near the cathode outlet is almost zero, indicating a dry zone away from the cathode inlet. We can also see that different temperature profiles 
lead to different lengths of the dry zone, which is longer when larger temperature gradients are applied. It is worth noticing that the highest water saturation is observed near the cathode inlet. Water builds up from a short length away from the cathode inlet. The maximum water saturation is around $15 \%$ for all temperature gradients. The strategy of simultaneously decreasing platinum loading and increasing the temperature along the gas flow direction effectively reduces the liquid water content towards the cathode outlet.
(a)
(b)
(c)
(d)

(e)
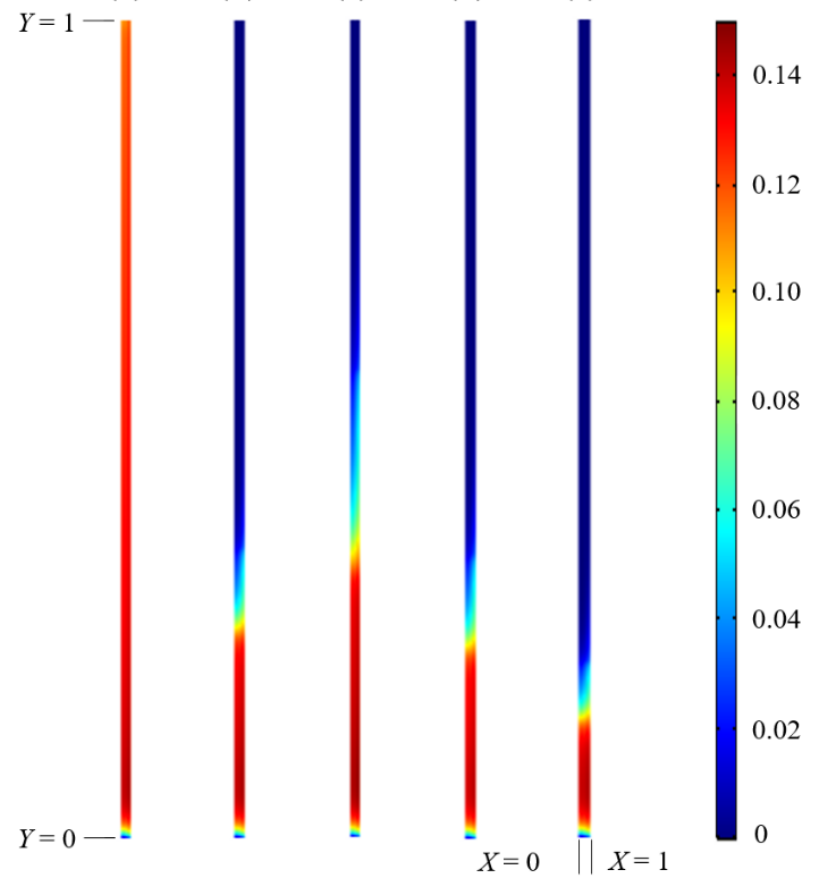

Fig. 14 Profile of water saturation inside cathode channel at cell voltage of $0.3 \mathrm{~V}$ with various temperature gradients.

(a) $T_{\text {in }}=T_{\text {out }}=60^{\circ} \mathrm{C}$; (b) $T_{\text {in }}=45^{\circ} \mathrm{C}, T_{\text {out }}=70{ }^{\circ} \mathrm{C}$; (c) $T_{\text {in }}=50^{\circ} \mathrm{C}, T_{\text {out }}=60{ }^{\circ} \mathrm{C}$; (d) $T_{\text {in }}=50^{\circ} \mathrm{C}, T_{\text {out }}=70{ }^{\circ} \mathrm{C}$; (2) $T_{\text {in }}$ $=50^{\circ} \mathrm{C}, T_{\text {out }}=80^{\circ} \mathrm{C} ; X=0-\mathrm{GDL}-$ channel interface, $X=1-$ channel outer boundary, $Y=0-$ cathode inlet, $Y=1-$ cathode outlet, $L=15 \mathrm{~cm}$, Pt loadings decreases from 0.4 to $0.3 \mathrm{mg} \mathrm{cm}^{-2}$ from the cathode inlet to the outlet. $L=15$ $\mathrm{cm}, R H_{\text {inlet }}=100 \%, \xi_{\mathrm{a}}=1.5, \xi_{\mathrm{c}}=3.0$. 
Table 2 Summary of the results of various operating strategies

\begin{tabular}{|c|c|c|c|c|c|c|c|c|c|c|}
\hline \multicolumn{2}{|c|}{ Graded $m_{\mathrm{Pt}, \mathrm{c}}\left(\mathrm{mg} \mathrm{cm}^{-2}\right)$} & \multicolumn{2}{|c|}{ Graded $T\left({ }^{\circ} \mathrm{C}\right)$} & \multicolumn{2}{|c|}{ Uniformly distributed } & \multirow{2}{*}{$\begin{array}{l}\text { Improved } \\
i \text { at } 0.3 \mathrm{~V}\end{array}$} & \multirow{2}{*}{$\begin{array}{l}\text { Improved } \\
i \text { at } 0.6 \mathrm{~V}\end{array}$} & \multirow{2}{*}{$\begin{array}{c}\text { Saved } \\
\text { Pt }\end{array}$} & \multirow{2}{*}{$\begin{array}{c}S \\
\text { at } 0.3 \mathrm{~V}\end{array}$} & \multirow{2}{*}{$\begin{array}{c}S \\
\text { at } 0.6 \mathrm{~V}\end{array}$} \\
\hline inlet & outlet & inlet & outlet & $m_{\mathrm{Pt}, \mathrm{c}}$ & $T$ & & & & & \\
\hline \multirow{2}{*}{0.4} & \multirow{2}{*}{0.3} & \multirow{2}{*}{45} & \multirow{2}{*}{70} & 0.4 & 45 & $40.5 \%$ & $85.5 \%$ & \multirow{2}{*}{$12.5 \%$} & \multirow{2}{*}{$1.17 \%$} & \multirow{2}{*}{$18.66 \%$} \\
\hline & & & & $0.35^{*}$ & $57.5^{*}$ & $2.13 \%$ & $-12.6 \%$ & & & \\
\hline \multirow{2}{*}{0.4} & \multirow{2}{*}{0.3} & \multirow{2}{*}{50} & \multirow{2}{*}{60} & 0.4 & 50 & $12.4 \%$ & $25.4 \%$ & \multirow{2}{*}{$12.5 \%$} & \multirow{2}{*}{$6.19 \%$} & \multirow{2}{*}{$5.95 \%$} \\
\hline & & & & $0.35^{*}$ & $55^{*}$ & $2.44 \%$ & $-9.3 \%$ & & & \\
\hline \multirow{2}{*}{0.4} & \multirow{2}{*}{0.3} & \multirow{2}{*}{50} & \multirow{2}{*}{70} & 0.4 & 50 & $27.3 \%$ & $46.8 \%$ & \multirow{2}{*}{$12.5 \%$} & \multirow{2}{*}{$2.97 \%$} & \multirow{2}{*}{$17.66 \%$} \\
\hline & & & & $0.35^{*}$ & $60^{*}$ & $2.45 \%$ & $-11.9 \%$ & & & \\
\hline \multirow{2}{*}{0.4} & \multirow{2}{*}{0.3} & \multirow{2}{*}{50} & \multirow{2}{*}{75} & 0.4 & 50 & $34.1 \%$ & $54.9 \%$ & \multirow{2}{*}{$12.5 \%$} & \multirow{2}{*}{$5.77 \%$} & \\
\hline & & & & $0.35^{*}$ & $62.5^{*}$ & $2.46 \%$ & $-12.2 \%$ & & & $22.04 \%$ \\
\hline & & & & 0.4 & 35 & $69.0 \%$ & $259.7 \%$ & & & \\
\hline 0.4 & $0.2 J$ & & OJ & $0.325^{*}$ & $50^{*}$ & $1.25 \%$ & $-16.0 \%$ & $10.0 \%$ & $4 . J 3 \%$ & 29.2070 \\
\hline 0 & ? & & & 0.4 & 40 & $45.8 \%$ & $124.1 \%$ & 1000 & 0 & 10 \\
\hline 0.4 & 0.25 & 40 & 03 & $0.325^{*}$ & $52.5^{*}$ & $1.66 \%$ & $-15.0 \%$ & $10.0 \%$ & 0.1170 & $21.04 \% 0$ \\
\hline & & & & 0.4 & 45 & $38.2 \%$ & $71.2 \%$ & & & \\
\hline 0.4 & 0.25 & 45 & 70 & $0.325^{*}$ & $57.5^{*}$ & $1.22 \%$ & $-12.6 \%$ & $18.8 \%$ & $8.17 \%$ & $23.27 \%$ \\
\hline & & & & 0.4 & 50 & $10.5 \%$ & $19.8 \%$ & & & \\
\hline 0.4 & 0.25 & 50 & 00 & $0.325^{*}$ & $55^{*}$ & $0.55 \%$ & $-6.3 \%$ & $18.8 \%$ & $15.1 / \%$ & $9.11 \%$ \\
\hline
\end{tabular}

$S$ - normalized standard variance of current density along the GDL-CL interface at the cathode, calculated by Eq. (44)

* - the average value of the inlet and outlet

\section{Conclusions}

The concept of graded distributions of platinum loading and the operating temperature was achieved by a house-made segmented fuel cell unit, consisting of five individual segments operated with different platinum loading and temperature along the gas flow direction. Since counter flow mode was applied, the temperature profiles were opposite at the cathode and anode, with increasing temperature at the cathode and decreasing temperature at the anode. Various gradients of platinum loading and temperature were numerically studied and experimentally validated. The optimal profiles of platinum loading and temperature 
were searched to simultaneously save the usage of platinum, improve the cell performance and maintain the homogeneity of current density.

The increase in temperature towards the cathode outlet increased the water carrying capacity of the gas mixture at the cathode, leading to a remarkable decrease in liquid water content, an increases in effective oxygen diffusion coefficient through the porous electrode, as well as an increase in reaction activity, along the gas flow direction. Integrated with the decrease in platinum loading towards the outlet, a considerable amount of precious catalyst is saved, without worsening the cell performance and current density homogeneity along the gas flow direction. Thus, simultaneously increasing temperature and decreasing platinum loading towards the cathode outlet is a promising strategy.

The gradients of platinum loading and temperature must be in a reasonable range. The large increasing gradient of temperature gradient leads to a significant membrane and ionomer dehydration and dilution of oxygen and then a decrease in current density near the cathode outlet. The large decreasing gradient of platinum loading results in a low current density near the cathode outlet, which cannot be compensated by the increasing temperature due to the elevated proton transport resistance and starvation of oxygen at high temperature. When the platinum loading is $0.4 \mathrm{mg} \mathrm{cm}^{-2}$ at the cathode inlet and the operating temperature increases from $35{ }^{\circ} \mathrm{C}$ to $65{ }^{\circ} \mathrm{C}$ towards the outlet, the platinum gradient of $0.01 \mathrm{mg} \mathrm{m}^{-3}$ saved $18.8 \%$ platinum and improved the current density by $69 \%$ at $0.3 \mathrm{~V}$, with a normalized standard variance of current density of $4.55 \%$.

\section{Declaration of interest statement}

The authors declare that there is no conflict of interest.

\section{Acknowledgement}

The authors acknowledge the National Natural Science Foundation of China $(21522603,21878129$, 21978118), Excellent Youth Foundation of Jiangsu Scientific Committee (BK20140011), the Natural Science Foundation of Jiangsu province of China (BK20170530), the start-up funding for young researchers of Jiangsu University (16JDG061) and the Innovation and Creation program of Jiangsu province of China (2016-32). The authors also acknowledge the support received from project STIM-REI, contract number: 
KK.01.1.1.01.0003, funded by the European Union through the European Regional Development Fund the Operational Programme Competitiveness and Cohesion 2014-2020 (KK.01.1.1.01.).

\section{References}

1. St-Pierre J, Wilkinson DP. Fuel cells: a new, efficient and cleaner power sources. AIChE J. $2001 ; 47: 1482-1486$.

2. Debe MK. Electrocatalyst approaches and challenges for automotive fuel cells. Nature. 2012;486:4351.

3. Kawase M, Sato K, Mitsui R, et al. Electrochemical reaction engineering of polymer electrolyte fuel cell. AIChE J. 2017;63:249-256.

4. Huang YX, Cheng CH, Wang XD, Jang JY. Effects of porosity gradient in gas diffusion layers on performance of proton exchange membrane fuel cells. Energy 2010;35:4786-4794.

5. Weng FB, Hsu CY, Su MC. Experimental study of micro-porous layers for PEMFC with gradient hydrophobicity under various humidity conditions. Int. J. Hydrogen Energy 2011;36:13708-13714.

6. Wei Z, Su K, Sui S, He A, Du S. High performance polymer electrolyte membrane fuel cells (PEMFCs) with gradient Pt nanowire cathodes prepared by decal transfer method. Int. Hydrogen Energy $2015 ; 40: 3068-3074$.

7. Xing L, Shi W, Su H, et al. Membrane electrode assemblies for PEM fuel cells: A review of functional graded design and optimization. Energy 2019;177:445-464.

8. Roshandel R, Farhanieh B, Saievar-Iranizad E. The effects of porosity distribution variation on PEM fuel cell performance. Renew Energy 2005;30:1557-1572.

9. Zhan Z, Xiao J, Li D, Pan M, Yuan R. Effects of porosity distribution variation on the liquid water flux through gas diffusion layers of PEM fuel cells. J. Power Sources 2006;160:1041-1048.

10. Tang H, Wang S, Pan M, Yuan R. Porosity-graded micro-porous layers for polymer electrolyte membrane fuel cells. J. Power Sources 2007;166:41-46.

11. Chen F, Chang M-H, Hsieh P-T. Two-phase transport in the cathode gas diffusion layer of PEM fuel cell with a gradient in porosity. Int. J. Hydrogen Energy 2008;33:2525-2529. 
12. Chun JH, Jo DH, Kim SG, et al. Development of a porosity graded micro porous layer using thermal expandable graphite for proton exchange membrane fuel cells. Renew. Energy 2013;58:28-33.

13. Zhang Y, Verma A, Pitchumani R. Optimum design of polymer electrolyte membrane fuel cell with graded porosity gas diffusion layer. Int. J. Hydrogen Energy 2016;41:8412-8426.

14. Song D, Wang Q, Liu Z et al. A method for optimizing distributions of Nafion and Pt in cathode catalyst layers of PEM fuel cells. Electrochim. Acta 2005;50:3347-3358.

15. Xie Z, Navessin T, Shi K, Chow R, Wang Q, et al. Functionally graded cathode catalyst layers for polymer electrolyte fuel cells: II. Experimental study of the effect of Nafion distribution. J. Electrochem. Soc. 2005;152:A1171-A1179.

16. Herden S, Riewald F, Hirschfeld JA, Perchthaler M. In-plane structuring of proton exchange membrane fuel cell cathodes: effect of ionomer equivalent weight structuring on performance and current density distribution. J. Power Sources 2017;355:36-43.

17. Xing L, Shi W, Das PK, Scott K. Inhomogeneous distribution of platinum and ionomer in the porous cathode to maximize the performance of a PEM fuel cell. AIChE J. 2017;63:4895-4910.

18. Antoine O, Bultel Y, Ozil P, Durand R. Catalyst gradient for cathode active layer of proton exchange membrane fuel cell. Electrochim. Acta 2000;45:4493-4500.

19. Santis M, Freunberger SA, Reiner A, Büchi FN. Homogenization of the current density in polymer electrolyte fuel cells by in-plane cathode catalyst gradients. Electrochim Acta 2006;51:5383-5393.

20. Prasanna M, Cho EA, Kim HJ, Oh IH, Lim TH, et al. Performance of proton exchange membrane fuel cells using the catalyst-gradient electrode technique. J. Power Sources 2007;166:53-58.

21. Lee SY, Kim HJ, Kim KH, et al. Gradient catalyst coating for a proton exchange membrane fuel cell operation under nonhumidified conditions. Electrochem Solid-State Lett 2007;10:B166-B169.

22. Taylor AD, Kim EY, Humes VP, Kizuka J, Thompson LT. Inkjet printing of carbon supported platinum 3-D catalyst layers for use in fuel cells. J. Power Sources 2007;171:101-106.

23. Srinivasarao M, Bhattacharyya D, Rengaswamy R. Optimization studies of a polymer electrolyte membrane fuel cell with multiple catalyst layers. J. Power Sources 2012;206:197-203. 
24. Roshandel R, Ahmadi F. Effects of catalyst loading gradient in catalyst layers on performance of polymer electrolyte membrane fuel cells. Renew. Energy 2013;50:921-931.

25. Su H, Liang H, Bladergroen BJ, Linkov V, Pollet BG, et al. Effect of platinum distribution in dual catalyst layer structured gas diffusion electrode on the performance of high temperature PEMFC. J. Electrochem. Soc. 2014;161:F506-F512.

26. Xing L, Wang Y, Das PK, Scott K, Shi W. Homogenization of current density of PEM fuel cell by inplane graded distributions of platinum loading and GDL porosity. Chem. Eng. Sci. 2018;192:699-713.

27. Zheng Z, Yang F, Lin C, Zhu F, Shen S, Wei G, Zhang J. Design of graded cathode catalyst layer (CCL) structure for mitigating Pt degradation in proton exchange membrane fuel cells (PEMFCs) using mathematical method. J. Power Sources 2020;451:227729.

28. Rabissi C, Zago M, Gazdzicki P, Guetaz L, Escribano S, Grahl-Madsen L, Casalegno A. A locally resolved investigation on direct methanol fuel cell uneven components fading: Local cathode catalyst layer tuning for homogeneous operation and reduced degradation rate. J. Power Sources 2018;404:135-148.

29. Djilali N. Computational modelling of polymer electrolyte membrane (PEM) fuel cells: challenges and opportunities. Energy 2007;32:269-280.

30. Siegel C. Review of computational heat and mass transfer modelling in polymer-electrolyte-membrane (PEM) fuel cells. Energy 2008;33:1331-1352.

31. Weber A, Borup RL, Darling RM, et al. A critical review of modelling transport phenomena in polymer-electrolyte fuel cells. J. Electrochem. Soc. 2014;161:F1254-F1299.

32. Shao Y, Yin G, Wang Z, Gao Y. Proton exchange membrane fuel cell from low temperature to high temperature: material challenges. J. Power Sources 2007;167:235-242.

33. Penga Z, Pivac I, Barbir F. Experimental validation of variable temperature flow field concept for proton exchange membrane fuel cells. Int. J. Hydrogen Energy 2017;42:26084-26093.

34. Xing L, Liu X, Alaje T, et al. A two-phase flow and non-isothermal agglomerate model for a proton exchange membrane (PEM) fuel cell. Energy 2014;73:618-634. 
35. Bender G., Wilson M.S., Zawodzinski T.A. Further refinement in the segmented cell approach to diagnosing performance in polymer electrolyte fuel cells, J. Power Sources. 2003;123:163-171.

36. Kirsch S., Hanke-Rauschenbach R., Stein, B., Kraume R., Sundmacher K. The electro-oxidation of $\mathrm{H}_{2}$, CO in a model PEM fuel cell: oscillations, chaos, pulses, J. Electrochem. Soc. 2013;160:F436F446.

37. Immerz C., Schweins M., Trinke P., Bensmann B., Paidar M., Bystron T., Bouzek K., HankeRauschenbach R. Experimental characterization of inhomogeneity in current density and temperature distribution along a single-channel PEM water electrolysis cell, Electrochim. Acta. 2018;260:582-588.

38. Xing L, Xu Y, Penga Z, Xu Q, Su H, Shi W, Barbir F. A novel flow field with controllable pressure gradient to enhance mass transport and water removal of PEM fuel cells. AIChE J. 2020,66:e16957.

39. Barbir F. PEM fuel cells: theory and practice. 1st ed. Oxford: Elsevier Academic Press; 2005.

40. Sun W, Peppley BA, Karan K. An improved two dimensional agglomerate cathode model to study the influence of catalyst layer structural parameters. Electrochim. Acta. 2005;50:3359-3374.

41. Marr C., Li X. Composition and performance modelling of catalyst layer in a proton exchange membrane fuel cell. J. Power Sources 1999;77:17-27.

42. Parthasarathy A., Srinivasan S., Appleby J. Temperature dependence of the electrode kinetics of oxygen reduction at the platinum Nafion interface - a microelectrode investigation, J. Electrochem. Soc. 1992;139:2530-2537.

43. Xing L, Song X, Scott K, Pickert V, Cao W. Multi-variable optimisation of PEMFC cathodes based on surrogate modelling. Int. J. Hydrogen Energy 2013;38:14295-14313.

44. Xing L, Cai Q, Xu C, Liu C, Scott K, Yan Y. Numerical study of the effect of relative humidity and stoichiometric flow ratio on PEM (proton exchange membrane) fuel cell performance with various channel lengths: an anode partial flooding modelling. Energy 2016;106:631-645.

45. Xing L, Cai Q, Liu X, Liu C, Scott K, Yan Y. Anode partial flooding modelling of proton exchange membrane fuel cells: optimisation of electrode properties and channel geometries. Chem. Eng. Sci. 2016;146:88-103. 
46. Xing $\mathrm{L}, \mathrm{Xu} \mathrm{Y}$, Das $\mathrm{PK}$ et al. Numerical matching of anisotropic transport processes in porous electrodes of proton exchange membrane fuel cells. Chem. Eng. Sci. 2019;195:127-140.

47. Khajeh-Hosseini-Dalasm N., M.J. Kermani, D.G. Moghaddam and J.M. Stockie, A parametric study of cathode catalyst layer structural parameters on the performance of a PEM fuel cell. Int. J. Hydrogen Energy, 2013;35:2417-2427.

48. Xing L, Mamlouk M, Kumar R, Scott, K. Numerical investigation of the optimal Nafion ionomer content in the cathode catalyst layer: An agglomerate two-phase flow modelling. Int. J. Hydrogen Energy 2014;39:9087-9104.

49. Suzuki T, Kudo K, Morimoto Y. Model for investigation of oxygen transport limitation in a polymer electrolyte fuel cell. J. Power Sources 2013;222:379-389.

50. Takamura Y, Nakashima E, Yamada H, Tasaka A, Inaba M. Effects of temperature and relative humidity on oxygen permeation in Nafion and sulfonated poly (Arylene Ether Sulfone). ECS Trans. 2008; $16: 881-889$.

51. Nonoyama N, Okazaki S, Weber AZ, Ikogiand Y, Yoshida T. Analysis of oxygen-transport diffusion resistance in proton exchange-membrane fuel cells. J. Electrochem. Soc. 2011;158:B416-B423.

52. Springer TE, Zawodzinski TA, Gottesfeld S. Polymer electrolyte fuel cell model. J. Electrochem. Soc. $1991 ; 138: 2334-2342$. 
